\title{
Rank Correlation Plots for Use With Correlated Input Variables in Simulation Studies
}




\section{DISCLAIMER}

This report was prepared as an account of work sponsored by an agency of the United States Government. Neither the United States Government nor any agency Thereof, nor any of their employees, makes any warranty, express or implied, or assumes any legal liability or responsibility for the accuracy, completeness, or usefulness of any information, apparatus, product, or process disclosed, or represents that its use would not infringe privately owned rights. Reference herein to any specific commercial product, process, or service by trade name, trademark, manufacturer, or otherwise does not necessarily constitute or imply its endorsement, recommendation, or favoring by the United States Government or any agency thereof. The views and opinions of authors expressed herein do not necessarily state or reflect those of the United States Government or any agency thereof. 


\section{DISCLAIMER}

Portions of this document may be illegible in electronic image products. Images are produced from the best available original document. 
Issued by Sandia National Laboratories, operated for the United States Department of Energy by Sandia Corporation.

NOTICF: This report was prepared as an account of work sponsored by an agency of the United States Government. Neither the United States Government nor any agency thereof, nor any of their employees, nor any of their contractors, subcontractors, or their employees, makes any warranty, express or implied, or assumes any legal liability or responsibility for the accuracy, completeness, or usefulness of any information, apparatus, product, or process disclosed, or represents that its use would not infringe privately by ted rects imply its endorsement, recommendation, or faving by the United States Government. any agency thereof or any of their contractors or subcontractors. The views and opinions any agency thereof ox any o theins and opinions Government, any agency thereof or any of their contractors or subcontractors. 
SAND80-1903

Unlimited Release

Printed November, 1980

Rank Correlat on Plots for Use with Correlated Input Variables in
Simulation Studies

Ronald L. Iman

Statistics and Computing Division 1223

Sandia Laboratories

Albuquerque, New Mexico 87185

James M. Davenport

Department of Mathematics

Texas Tech University

Lubbock, Texas 79409

\begin{abstract}
A method for inducing a desired rank correlation matrix on multivariate input vectors for simulation studies has recently been developed by Iman and Conover (1980b). The primary intention of this procedure is to produce correlated input variables for use with computer models. Since this procedure is distribution free and allows the exact marginal distributions to remain intact it can be used with any marginal distributions for which it is reasonable to think in terms of correlation. In this paper we present a series of rank correlation plots based on this procedure when the marginal distributions are normal, loginormal, uniform and logunlform. These plots provide a convenlent tool for both aiding the modeler in determining the degree of dependence among input variables rather than guessing and for communicating with the modeler the effect of different correlation assumptions.
\end{abstract}


THIS PAGE LEFT BLANK INTENTIONALLY. 


\section{CONTENTS}

List of Figures................................v

List of Tables................................ vi1

I. Introduction.................................

II. Specifying the Rank Correlations......................4

III. A Review of the Method of Inducting Correlations...........6

[V. The Rank Correlation Scatterplots....................8

V. Sampling from Avallable Blvariate Data..................9

VI. Discusston...................................12

B1b1lography................................. 15

Appendix A. Scatterplots of Simulated "Jolnt"

Distributions........................ A-1

Appendix B. Tables of the Target Rank Correlations, Sample Rank Correlations and Sample Pearson Correlations for Each of the Ten Pairs of "Joint" Distributions................... B-1 
THIS PAGE LEFT BLANK INTENTIONALLY. 
Scatterpjots of the Original Data and the simulated Jolnt Distribution of Permeability and Porosity of the 3rd lenango 011 Sands In Pennsylvania..........

Scatterplots of the Original Data and the Simulated Jolnt Distribution of Flow Rate and Suspended Sediment for the Rio Grande River Near Bernali11o,

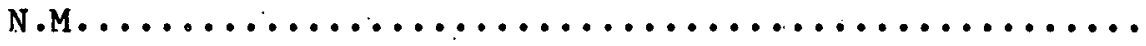

A-1 . Simulated Scatterplots of "Jointly" Distributed

Case 1: Normal Distribution vs Normal Distribution

A-2 Simulated Scatterplots of "Jolntly Distributed A-6 Random Variables with Specifled Target Rank to Correlations with Sample Size $=1000$.

Case 2: Normal Distribution vs Lognormal Distribution

A-3 Simulated Scatterplots of "Jointly" Distributed

Case 3: Normal Distribution vs Logunfform Distribution

\section{A-4 Simulated Scatterplots of "Jointly" Distributed}

Random Variables with Specified Target Rank

$A-14$

Correlations with Sample Size $=1000$.

Case 4: Normal Distribution vs Uniform Distribution

Simulated Scatterplots of "Jointly" Distributed

Case 5: Lognormal Distribution vs Lognormal Distribution

A-6 Simulated Scatterplots of "Jolntly" Distributed

Case 6: Lognormal Distribution vs Loguniform Distribution 


\section{List of Figures (Continued)}

Figure No

A-8

A-9

A-10
Figure Caption

Simulated Scatterplots of "Jointly" Distributed Random Varlables with Specifled Target Rank Correlations with Sample Size $=1000$.

Case 8: Loguniform Distribution vs Loguniform Distribution

Simulated Scatterplots of "Jointly" Distributed Random Vartables with Specifled Target Rauk Correlations with Sample Size $=1000$.

Case 9: Loguniform Distribution vs Uniform Diatribution.

Simulated Scatterplots of "Jolntly" Distributed Random Variables with Specified Target Rank Correlations with Sample Size $=1000$.

Case 10: Uniform Distribution vs Uniform Distribution.
Page No(s).

$A-30$

to

A-33

A-34

to

A-37

A-38

to

A-41 
Table No.

Table Caption

Page No.

B-1

Target Correlations and Reallzed Sample Correlations

for $\mathrm{N}=1000$; Normal Distribution vs Normal

Distribution.

B-2 Target Correlations and Realized Sample Correlations

for $\mathrm{N}=1000$; Normal Distribution vs Lognormal

$B-3$

Distribution.

B-3 Target Correlations and Reallzed Sample Correlations

B-4

for $\mathrm{N}=1000$; Normal Distribution vs Loguniform

Distribution.

B-4 Target Correlattons and Reallzed Sample Correlations

for $N=1000$; Normal Distribution vs Uniform

$B-2$

Distribution.

B-5 Target Correlations and Realized Sample Correlations for $N=1000$; Lognormal Distribution vs Lognormal Distribution.

B-6 Target Correlations and Reallzed Sample Correlations for $N=1000$; Lognormal Distribution vs Loguniform Distribution.

B-7 Target Correlations and Reallzed Sample Correlations for $\mathrm{N}=1000$; Lognormal Distribution vs Uniform Distribution.

B-8 Target Correlations and Realized Sample Correlations for $\mathrm{N}=1000$; Logunf form Distribution vs Loguniform Distribution.

B-9 Target Correlations and Realized Sample Correlations B-10 for $\mathrm{N}=1000$; Ioguniform Distribution vs Unt form Distribution.

B-10 Target Correlations and Realized Sample Correlations

for $N=1000$; Untform Distribution vs Uniform

Distribution. 
THIS PAGE LEFT BLANK INTENTIONALLY.

viii 
CORRELATION PLOTS

\section{INTRODUCTION}

Computer models are used widely to simulate the intricate relationships among variables in many areas of applications in order to estimate unknown quantities or predict future events. Investigation of techniques for efficiently selecting input values has led to the development of Latin hypercube sampling (LHS) by McKay, Conover and Beckman (1979) for those situations where it isapproprlate to consider the input as variables with associated distributions. Procedures for looking at the effect of different distributional assumptions on input variables have been examined in Iman and Conover (1980a).

While much effort has been expended toward the development of new statistical techniques for computer modeling, relatively 1 ittle attention has been given to the problem of incorporating the dependences that may exist among the input variables. Typically the model input variables are assumed to be Independent, bist the assumption of Independence among the Input variables may not be appropriate. Many situations exist in the "real world" where dependences or correlations do exist among the Input variables. That is, parameters, design varfables, control variables, etc. may be dependent upon one another. The design of an experiment, where the objective is to make broad inferences over the entire joint populations of Input varlables, that ignores these dependences is poorly concelved and certalnly not appropriate.

While there exist a few techniques for incorporating dependences among the input variables, within the context of this paper the method 
of Iman and Conover (1981) is reviewed and used to Induce the dependences among the input variables. This method is based on rank correlations, and the approach is based on the premise that rank correlation is a meaningful way to define dependences among variables that are monotonically related. This method is reviewed in Section III.

There are at least three reasons for using the concept of correlation, spectflcally rank correlation, as a vehicle to induce dependences among Input vartables. First, correlations are well understood by even the novice practitioner provided the raw data is beling used and these data caine frou normal probability distributions. Most all practitioners are familiar with the effect of varying values of the correlation coefficlent upon bivariate normal scatterplots and probability contours.

Second, a correlation coefflclent computed on raw data may lose meantng and Interpretation with data from non-normal populations or in the presence of outliers. However, rank correlation coefficlents can be quite meaningful in modeling situations where the variables are nonutonically rèlated and not necessartly normally distributed. Furthermore, In some situations such as the bivarate normal and bivarlate unfform, the values of the rank and Pearson correlation coefficients ate ussentially the same,

Third, it may make more sense to talk about iujuutune relationships, and hence rank correlations, because of the unusual behavior of the Pearson correlation coefficlent in certaln joint probabiltty discributions.

Consider the following case that involves logurimal distributions. Let $\mathrm{x}_{1} \sim \mathrm{N}\left(\mu_{1}, \sigma_{1}{ }^{2}\right)$ and $\mathrm{x}_{2} \sim \mathrm{N}\left(\mu_{2}, \sigma_{2}{ }^{2}\right)$. Furthermore, let $\mathrm{x}_{1}$ and $\mathrm{x}_{2}$ have a bivariate normal distribution with correlation coefficient denoted 
by $\rho\left(\mathrm{X}_{1}, \mathrm{X}_{2}\right)$. Now consider the two dimensional transformation defined by $Y_{1}=\exp \left(X_{1}\right)$ and $Y_{2}=\exp \left(X_{2}\right)$. It 18 natural to think of the joint distribution of $\mathrm{Y}_{1}$ and $\mathrm{Y}_{2}$ as a bivariate lognormal distribution. The correlation coefficlent for this joint pdf is given by

$$
\rho\left(Y_{1}, Y_{2}\right)=\frac{\exp \left[\rho\left(X_{1}, X_{2}\right) \sigma_{1} \sigma_{2}\right]-1}{\left[\left(\exp \left(\sigma_{1}{ }^{2}\right)-1\right)\left(\exp \left(\sigma_{2}{ }^{2}\right)-1\right)\right]^{1 / 2}}
$$

Therefore, it is easy to show that there exists a lower bound on $\rho\left(Y_{1}, Y_{2}\right)$ which is greater than -1 .

For example, let $\rho\left(\mathrm{X}_{1}, \mathrm{X}_{2}\right)=-1$ and $\sigma_{1}=\sigma_{2}=1$, then $\rho\left(\mathrm{Y}_{1}, \mathrm{Y}_{2}\right)$ cannot be less than $-e^{-1} \approx-.36788$. The fact that $\rho\left(Y_{1}, Y_{2}\right)$ cannot be less than $-e^{-1}$ makes interpretation of the correlation coefficient difficult for the novice practitioner. Therefore, it seems more appropriate in these cases to use the rank correlation coefficlent which st11l has range from -1 to +1 .

As a further illustration of this unusual behavior of the Pearson correlation coefficient consider the following: Let $\mathrm{Y}$ follow a lognormal distribution with range from 0.2 to 6.0 , where the lower limit is taken to be the lower .001 quantile and the upper $11 \mathrm{mlt}$ is taken to be the upper .001 quant1le. This corresponds to a normal distribution with mean = 0.91161 and standard deviation $=.55031$. Therefore, let $\sigma_{1}=\sigma_{2}=$ .55031 and $\rho\left(X_{1}, X_{2}\right)=-1$. In the above formula, which produces a lower bound of $\rho\left(Y_{1}, Y_{2}\right)=.7387$.

Such a bivarlate lognormal distribution was sampled using the Iman and Conover method. Some summary data are glven in Table B-5 in Appendix B. The fact that some of the sample Pearson correlation coefficients exceed this lower bound could be due to a couple of reasons. The first is simply 
round-off error. The second is the fact that the bivarlate sample generated uslng this method may not be a true bivariate lognormal ditribution. However, the results obtalned here are amazingly close and hence it is felt that the bivariate plots produced and exhlbited in this paper accurately reflect what the actual joint pdf is in each case considered.

In conclusion, it ts felt that rank correlations are a meaningful and appropriate way to Induce dependences among input variableo.

In Gection II, the problem of setting the valuco of the lauk correlation coefficlent that will be used to tnduce the desired dependence between the two variables is discussed. Section III presents a review of the Iman and Conover technique, while Section IV presents the series of rank correlation plots based on this procedure and which are exhlbited In Appendix A. Section $V$ contains an additional application, and the final section contalns a discussion.

\section{Specifying the Rank Correlations}

In any type of computer modeling lnvolving random sampling of the Input variables, whether it is simple random sampling, stratified sampling or Latin hypercube sampling, the validity of the model output depends to a great extent on how closely the sampled jolnt distribution nf the input varlables agrees with the true folnt distribution. That is, if a correlation etructure exists among the input varlabies, but the actual sampling takes place as if the Input variables were Independent, the theoretical properties of the statistics formed from the output may no longer be valid. Estimators intended to be unbiased or consistent may not be. The 
procedure presented in Iman and Conover (1981) can be expected to bring the folnt distribution of the input variables closer to the true foint distribution than wo ld be attained under the faulty assumption of Independence.

Therefore, it is extremely important that existing correlation structure be spectfled as accurately as posstble. The modeler may find to some degree one of the following three situations. He may have some knowledge of the correlation values and the distributions of the varlables. The knowledge is usually based upon his experlence as the "subject area specialist," and no other data are available.

The second situation is a silght improvement over the first. The modeler may or may not have knowledge of the correlation coefficlent values, but does possess knowledge of the distributions of the variables along with a basic idea of what the bivarlate plots should look like.

The third situation is where the modeler has actual bivarlate data Erom which marginal empirical distributions can be derived. These distributions may or may not look like the more common ones (normal, lognormal, uniform, etc.). In any case, a sample must be drawn that closely resembles the joint distribution of the bivariate data avallable.

There exist other situations of varying degree that the modeler may encounter, but $1 t$ is felt that at least in the three situations discussed above, a collection of blvarlate scatterplots that demonstrate the Iman and Conover method would ald the modeler in specifying the rank correlation values that exist between the input variables. These plots provide a convenlent tool for both alding the modeler in determining the degree of dependence among input varlables rather than guessing and for communicating with the modeler the effect of different correlation assumptions. 


\section{A Review of the Method of Inducing Correlations}

Suppose that a random row vector $\underset{\sim}{X}$ has a correlation matrix $\underset{\sim}{I}$. That is, the elements of $\underset{\sim}{\mathrm{X}}$ are uncorrelated. Let $\underset{\sim}{\mathrm{C}}$ be the desired target rank correlation matrix supplied by the user. Since $C$ is positive definte and symmetric, $\underset{\sim}{\mathrm{C}}$ may be written as $\underset{\sim}{\mathrm{C}}=\underset{\sim}{\mathrm{PP}}-$, where $\underset{\sim}{\mathrm{P}}$ is a lower triangular matrix. The Cholesky factorization scheme used by Scheuer and Stoller (1962) may be used to obtain the lower trlangular matrix $\underset{\sim}{\mathrm{P}}$. Then the

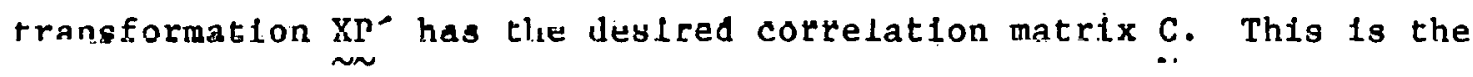
cheoretical basls for this method.

We begin by specifying a matrix $\underset{\sim}{R}$, of scores. Let the number of input variables be denoted by $K$, and let $N$ be the sample size. Let $\underset{\sim}{R}$ be an $N \times K$ matrix whose columns represent $K$ independent permutations of a set of scores $\{a(1)\}, 1=1,2, \ldots, N$. Each row of $\underset{\sim}{R}$, say $\underset{\sim}{\mathbb{R}_{1}}$, has $K$ components, where each component assumes one of the values $a(1), 1=1,2, \ldots, N$ w1th equal probability. Then the row vector $R_{1}$ has population correlation matrix $I_{\text {. }}$.

The scores $\{a(1)\}$ are the van der Waerden scores $\Phi^{-1}(1 /(N+1)$, $-1$

where $\Phi$ is the Inverse function of the standard normal distribution function. Hence each column of $\underset{\sim}{R}$ is a random permutation of the van der Waerden scores for a sample of sfze $N$. The authors have Investigated use of other scores and found the van der Waerden scores to have more desirable properties for generating the joint distribution.

While the expected correlation matrix assoctated with $\underset{\sim}{R}$ is $\underset{\sim}{ }$, the actual sample correlation matrlx of $\underset{\sim}{R}$, say $\underset{\sim}{T}$, may differ considerably from $\underset{\sim}{I}$ Hence, consider only realizations of $\underset{\sim}{R}$ which have distinct (non1dentical) columns, so that $\underset{\sim}{T}$ is positive definite and symmetric. 
Then there exists a lower triangular matrix $\underset{\sim}{Q}$ such that $\underset{\sim}{\mathrm{T}}=\underset{\sim \sim}{Q Q^{-}}$and hence $\left({\underset{\sim}{Q}}^{-1}\right) \underset{\sim}{T}\left(\mathbb{\sim}^{-1}\right)^{-}=\underset{\sim}{I}$. Therefore, $\underset{\sim}{\mathrm{R}}\left({\underset{\sim}{Q}}^{-1}\right)^{-}$w111 have row vectors that have an exact identity correlation structure. That 1s, the correlation natrix of $\mathrm{R}_{\mathcal{1}} \stackrel{(Q)}{ }^{-1}$, is exactly $I_{\sim}$

It is apparent that $\mathrm{R}_{\sim}^{*}=\underset{\sim}{\mathrm{R}}\left(\underset{\sim}{Q^{-1}}\right)^{-} \underset{\sim}{\mathrm{P}^{-}}$has row vectors that have $a$. correlation matrix exactly equal to $\underset{\sim}{C}$. Furthermore, the rank correlation matrlx of $\underset{\sim}{R^{*}}$, say $\underset{\sim}{M}$, should be close to $\underset{\sim}{C}$.

It only remalns to generate an NxK matrix of Input vectors, according to any desired method or distribution, as if the $K$ input random variables were Independent of each other. Then the values of the variable in each column are arranged so they have the same order (rank) as the corresponding column in $R^{*}$. Thus the sample rank correlation matrix of the input vectors will be 1dentical to the rank correlation matrix assoclated with $R^{*}$. Furthermore, the sample rank correlation matrix of the input vectors should be close to $\underset{\sim}{C}$, the desired rank correlation structure.

The Interested reader 1 s referred to Iman and Conover (1981) for some further investigation Into this method.

This method of Inducing rank correlation between varlables has the followling desirable propertles.

1) It is distribution free. It may be used with equal facility on all types of input distribition functions.

2) It is simple.

3) It can be applied to any sampling scheme for which correlated input variables could logically be considered, while preserving the intent of the sampling scheme. That $\mathrm{ls}$, the same numbers originally selected as Input values are retalned; only their pairing is affected to achleve 
the desired rank correlation. This means that in Latin hypercube sampling the integrity of the intervals is malntained. If some lattice structure is used for selection of values, that same structure is retalned.

4) The Identity of the marginal distributions on the Input variables Is maintained, as the pairing of the varlables does not change the numbers themselves.

\section{The Rank Corre1.at lon Scatterplots}

To aid the modeler in specifylng the rank correlation values that exist between the varlables, a series of scatterplots based on this procedure were produced. These plots are given in Appendix A.

The marginal distributions chosen were the normal, lognormal, untform and logunfform. It is felt that these are somewhat representative of the general types of distributions that a modeler may use. Howcver, any distribution can be used. The only requirement is that the distribution must be of such a nature that a sample can be drawn from that distribution. The specific distributions that were sampled arc defined by the following ranges. The normal and unfform worc given a rauge froth -3.0 to 3.0 , and the lognormal and 1.nguntform werc giveu a range of 0.2 to 6.0 . In the Ewo situations where the true ranges of the random variables are infintte, the lower lintt of the range is taken to be the lower .001 percentile and the upper limit of the range to taken to be the upper .001 
percentile. Every possible pairing of these four distributions were considered with the fol: owing values of the rank correlation coefficient; $0.0, \pm 0.25, \pm 0.50, \pm 0.75, \pm 0.90, \pm 0.95, \pm 0.99$ and \pm 0.9999 . In every case, a Latin lypercube sample was taken from each marginal distribution with sample size, $N=1000$. As mentloned earlier, other types of sampling of the marginals could be done. But for this paper only Latin hypercube samples were considered. Simple random samples of the marginals were Investigated but are not given, since there were no discernible differences between the scatterplots of these two types of sampling schemes. One interesting result occurs when any of the distributions is paired with the uniform distribution and the rank correlation coefficient is given the value of 0.9999 . The jolnt pdf's in these situations are very nearly' Identical to the cumulative distribution function of the distribution that was paired with the uniform distribution (apart from a scaling of the uniform distribution so that its range is from zero to one). As the rank correlation coefficient approaches negative one, the jolnt pdf of these two random variables approaches $1-F(x)$, where $F(x)$ is the cumulative distribution function of the distribution paired with the uniform distribution.

This is a very appealing property of this method of sampling with Induced correlation, and in general, would be a necessary requirement of any such sampling scheme.

\section{Sampling from Avallable Bivariate Data}

In Section II, the situation of actually having data from the process that is being modeled was discussed. Attention is restricted without loss 
of generality to blvariate distributions. The modeler could take this data and estimate the marglnal distributions. Sampling would then proceed as described in section III, using the estimated rank correlation coefficient as the target rank correlątion.

However, It may be very difficult to identify the "distributional family" from which these marginals come. Furthermore, 1t may be equally difficult to sample the estimated distribution function that is based on splines. Iherefore, the modeler may wish to sample directly from the marginal empirical distribution functions derived from the bivariate data. Two such examples are presented to illustrate this technique. The first is a set of $\mathrm{N}=24$ palrs of sample values that measure the permeability and porosity of the 3rd Venango 011 Sands in Pennsylvania. The data were taken from Musket $(1937, \mathrm{p} 103$ - 106). The sample rank correlation coefficlent for this set of data 1s 0.674 . This value was then used as a target rank correlation in this procedilre and the marginals were taken to be the empirical distribution functions. The origtnal data and the slüulatel jolnt distribution for this set of $N=24$ polnts are given in Figure 1 . This sampling procedure was able to "duplicate" this set of bivariate data very we11.

Since the sampling was done from the empirical distribution functions, the simulated sample values are identical to the original data points. What has clidiged is the pairing of the Individual pairs of points. In essence, what this procedure does to change the pairings of data points in such a way as to malntaln a rank correlation near the value of the target correlation.

If In the simulated sample we take a sample size larger than the number of original data points, then some (or all) of the original data polnts will 

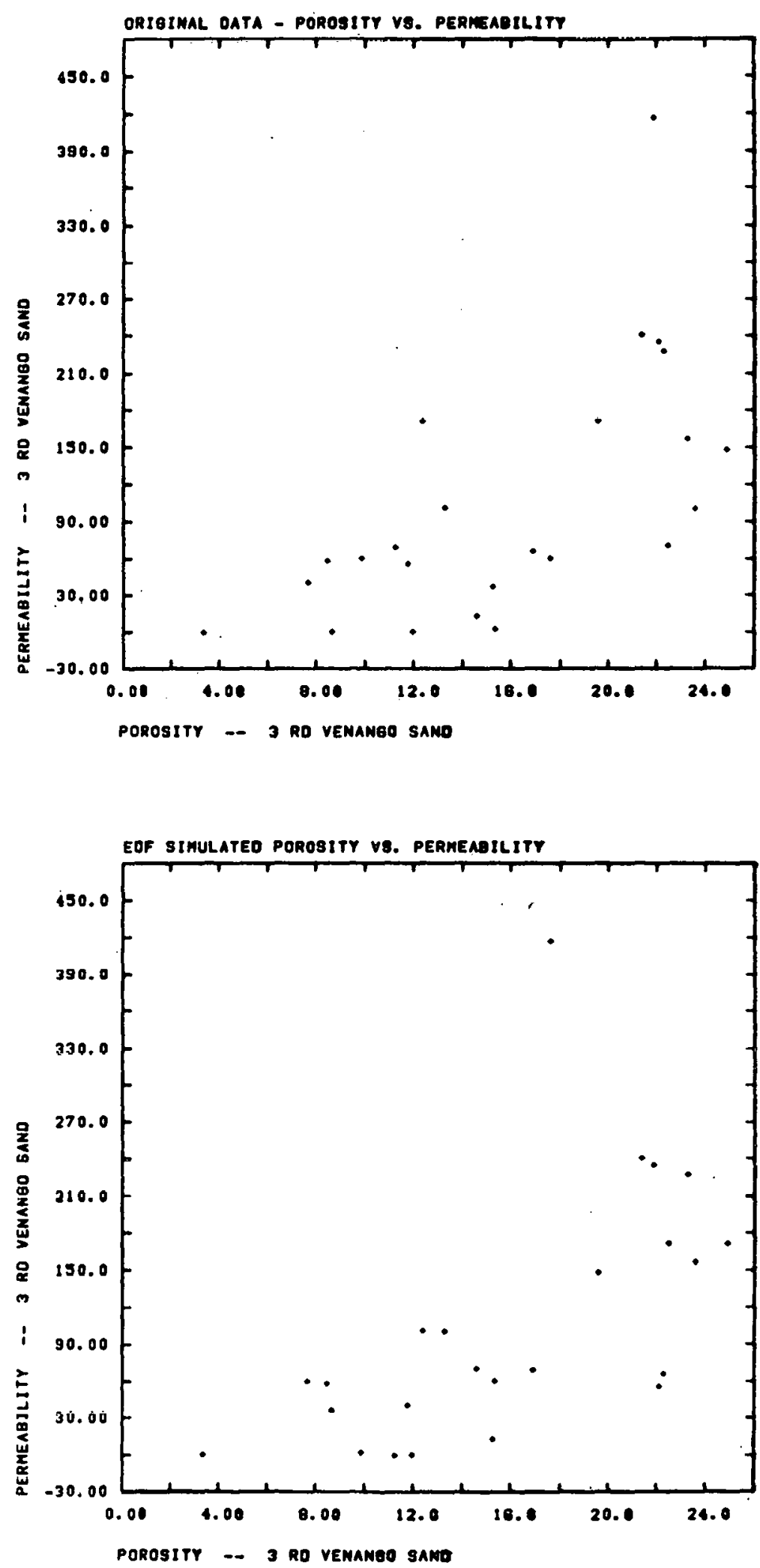

Figure 1

Scatterplots of the Original Data and the Simulated Joint Distribution of Permeability and Porosity of the 3rd Venango Oil Sands in Pennsylvania (taken from Musket (1937), p. 103-106). 
be repeated in the simulation sample. This procedure will palr these observations in such a way as to malntaln the rank correlation near the target correlation.

The foregoing "test" of thls sampling procedure was repeated on a second set of $N=305$ pairs of sample values that are measures of the flow rate and suspended sediment for the Rio Grande River near Bernallilo, New Mexico. The original data and simulated joint distribution are given as scatterplots in Figure 2. Aga1n, this sampling procedure "duplicated" the observed data quite well.

In summary, it is felt that when sampling from glven emplrical distribution functions, that the present sampling scheme can adequately reproduce a given set of blvariate observations, provided, of course, that the two varlables are monotonically related.

\section{Discussion}

Methods for patring observations on independent random varlables in order to Induce a rank correlation structure are reviewed in this paper, and a serles of scatterplots are presented to illustratc the procelure. Furthermore, the scatterplots can be used by the modeler as an ald ir: specifyling the rank correlations among the input varlables. This procedure has several advantages over eome of the othui procedures, but is not without its limftations.

First, this procedure cannot be used when the range space of the blvarlate random varlables $(X, Y)$ is not a product space. In such a case, 

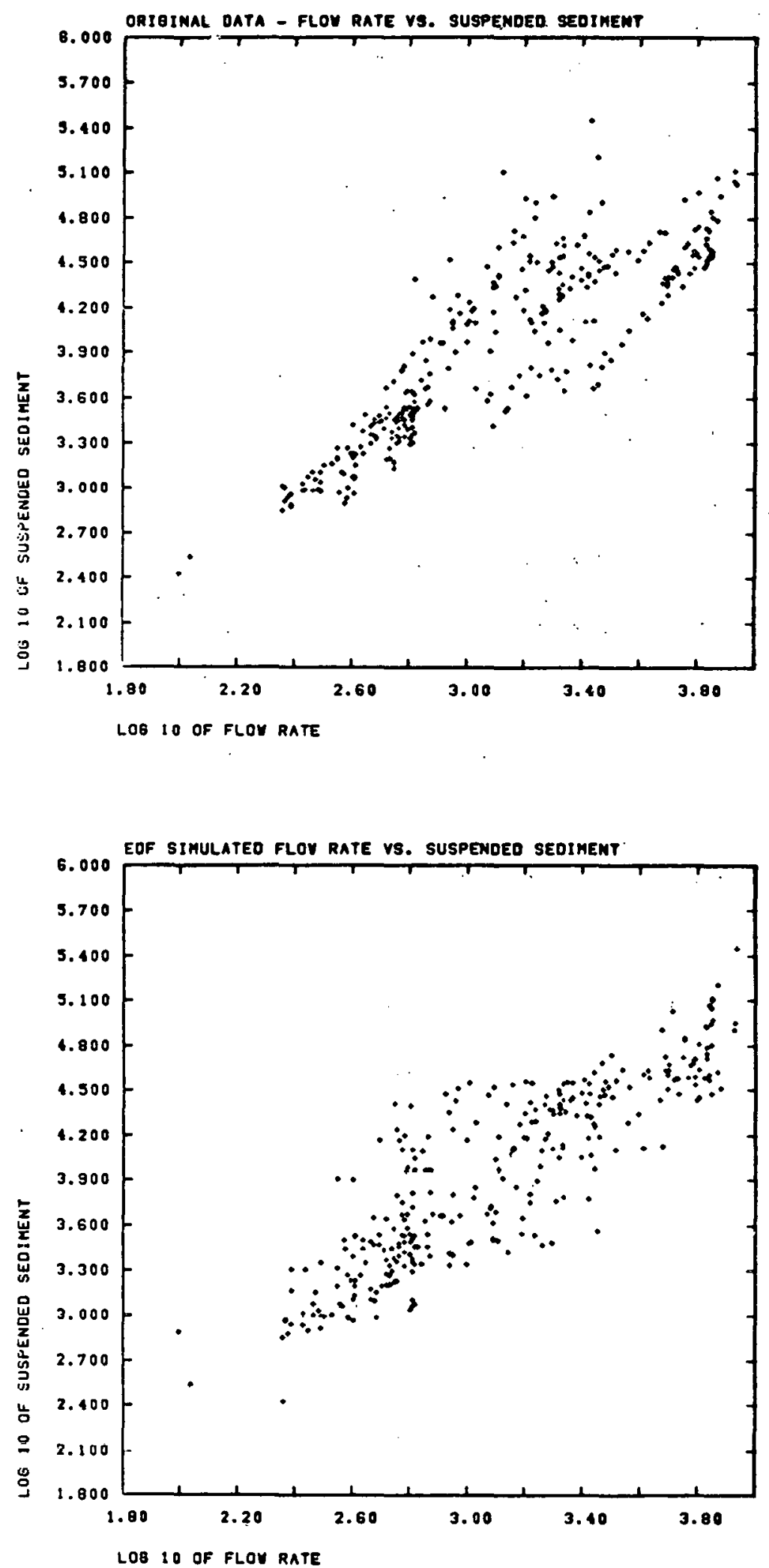

Figure 2

Scatterplots of the Original Data and the Simulated Joint Distribution of Flow Rate and suspended sediment for the Rio Grande River near Bernalillo, New Mexico - (taken from Love (1956), p. 380-381) 
sampling from the ranges of the marginals followed by appropriate pairings Is almost certainly going to produce palrs of points outside the range space of $(X, Y)$. In such cases, some other procedure of simulation would need to be used.

Secondly, a multivarlate distribution is much more complex than a mere collection of marginal distributions and a variance - covariance matrix. However, it is usualiy not possible to obtain more rigid spoolfications than those. In fact, it is more usual to find only the marginal input distributions specified with the correlation matrix defaulted to the identity matrix for simplicity. If correlations are appropriate, the Iman and Conover method of Inducing correlations on input variables would be a definite improvement. Of course, if more complete information about the multivariate input distribution is avallable, it should be used in the sampling scheme if methods are avallable for incorporating that information.

A recent technical report by Iman, navenport and Zclgler (1900) aL Sandia Laboratorles provides a user's manual and computer listings for implementing the methods discused in this paper. A copy of this report can be obtained from the first author on this paper. 
APPFNDIX A

Scatterplots of Simulated "Joint" Distributions

On the graphs which follow, the axes are labeled to indicate the distribution associated with the random variables which have been correlated. The numbers on the axes themselves correspond to the ranges used with the respective variables. 

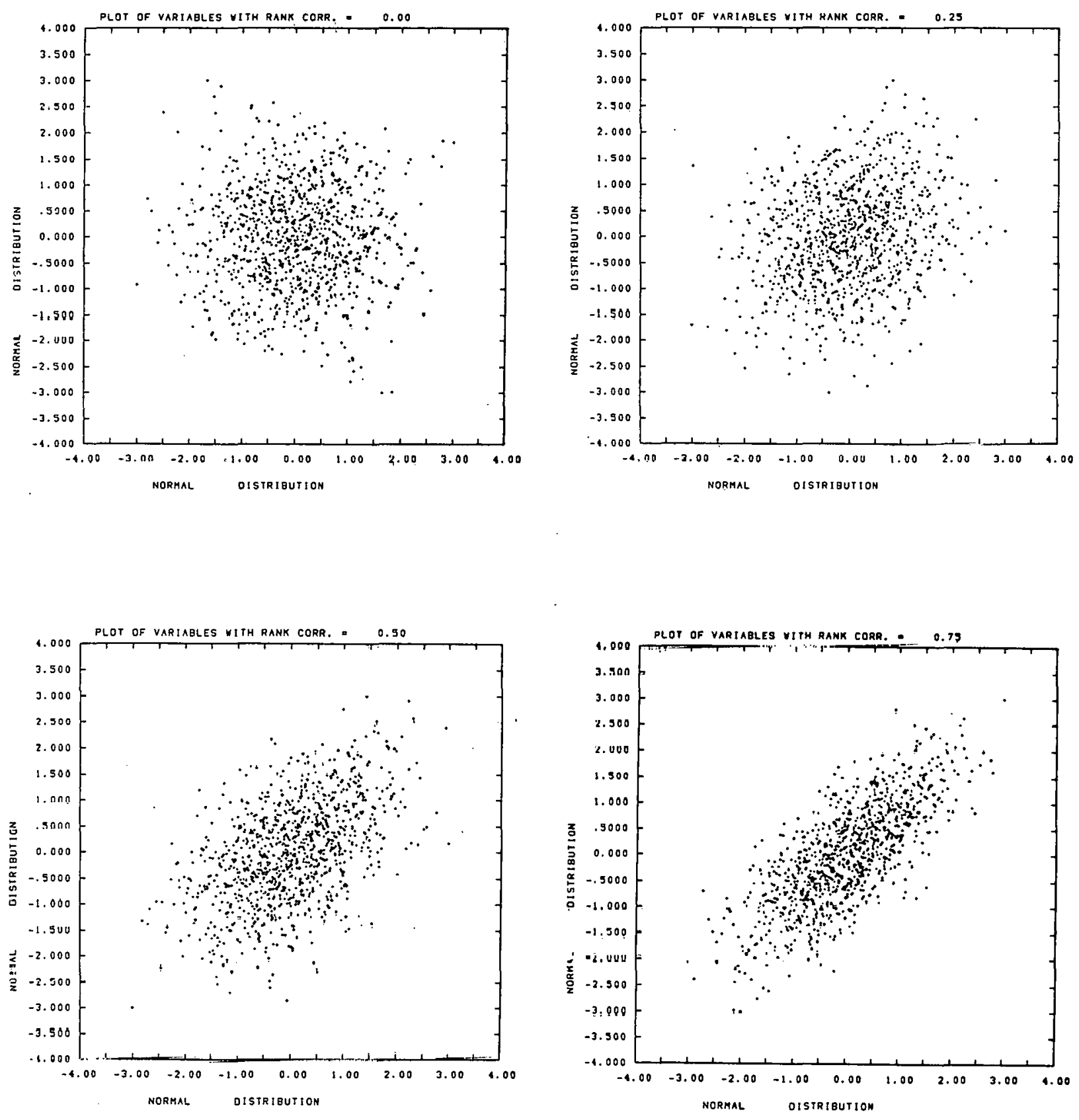

Fiqure $A-1$

Simulated Scatterplots of "Jointly" Distributed Random Variables with Specified Target Rank Correlations with Sample Size $=1000$. Case 1: Normal Distribution vs. Normal Distribution. 

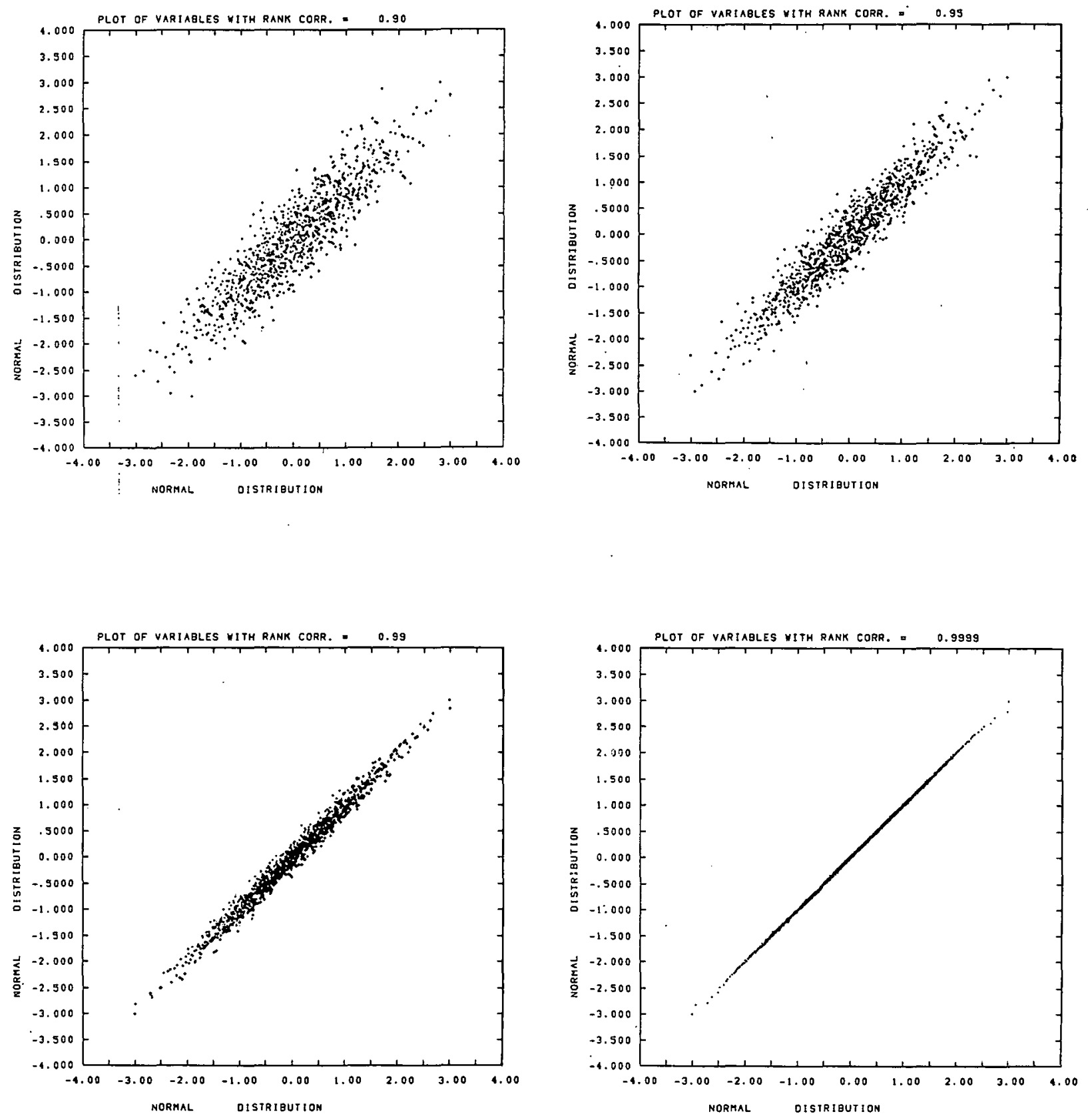

Figure $A-1$

Simulated Scatterplots of "Jointly" Distributed Random Variables with specified Target Rank Correlations with Sample Size $=1,000$. Case 1: Normal Distributions vs. Normal Distribution. 

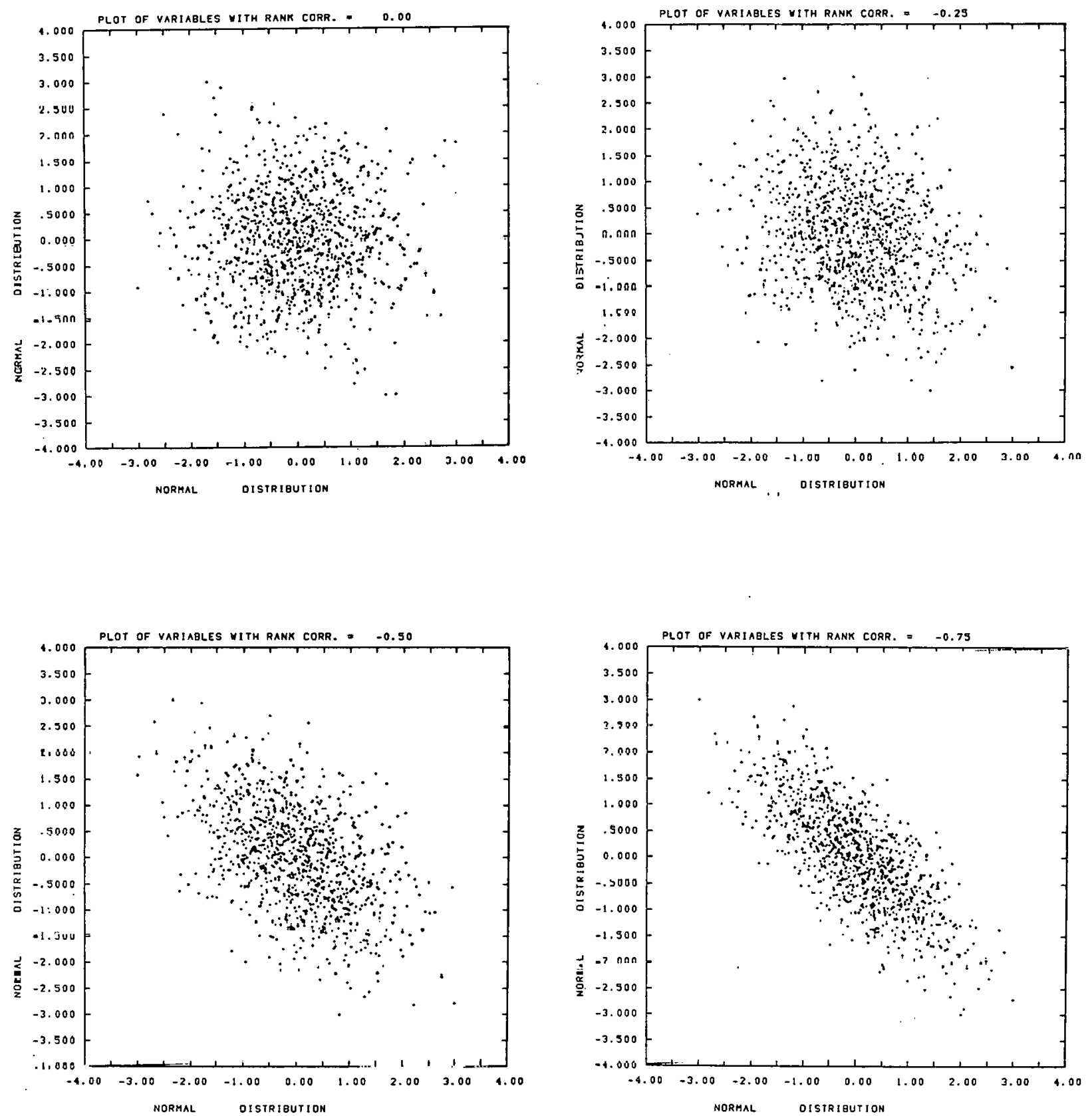

Figure $A=1$

Simulated Scatterplots of "Jointly" Distributed Random Variables with Specified Target Rank Correlations with Sample Size $=1000$.

Case 1: Normal Distribution vs. Normal Distribution. 

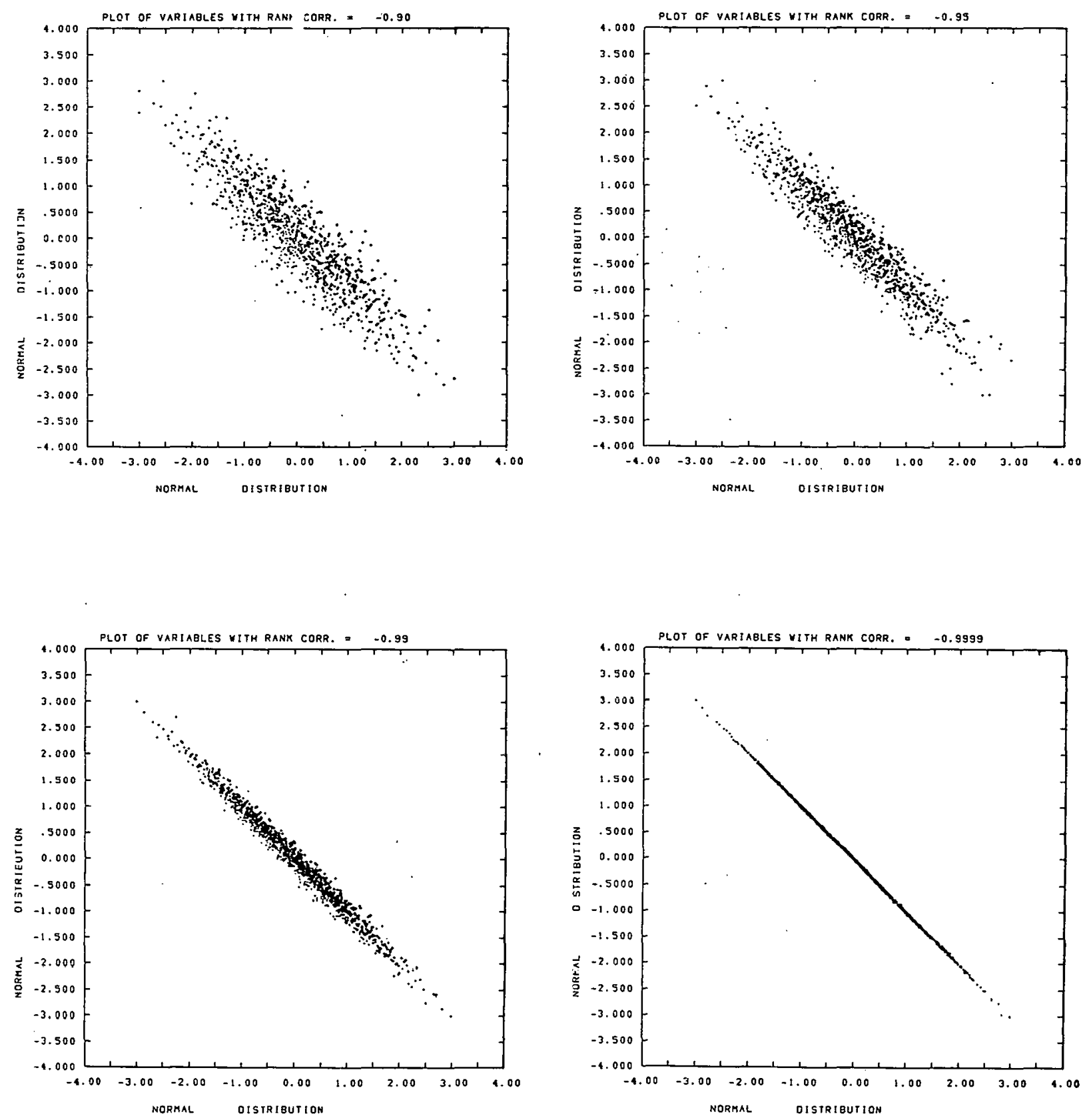

Figure $A-1$

Simulated Scatterplots of "Jointly" Distributed Random Variables with Specified Target Rank Correlations with Sample Size $=1000$. Case 1: Normal Distribution vs. Normal Distribution. 

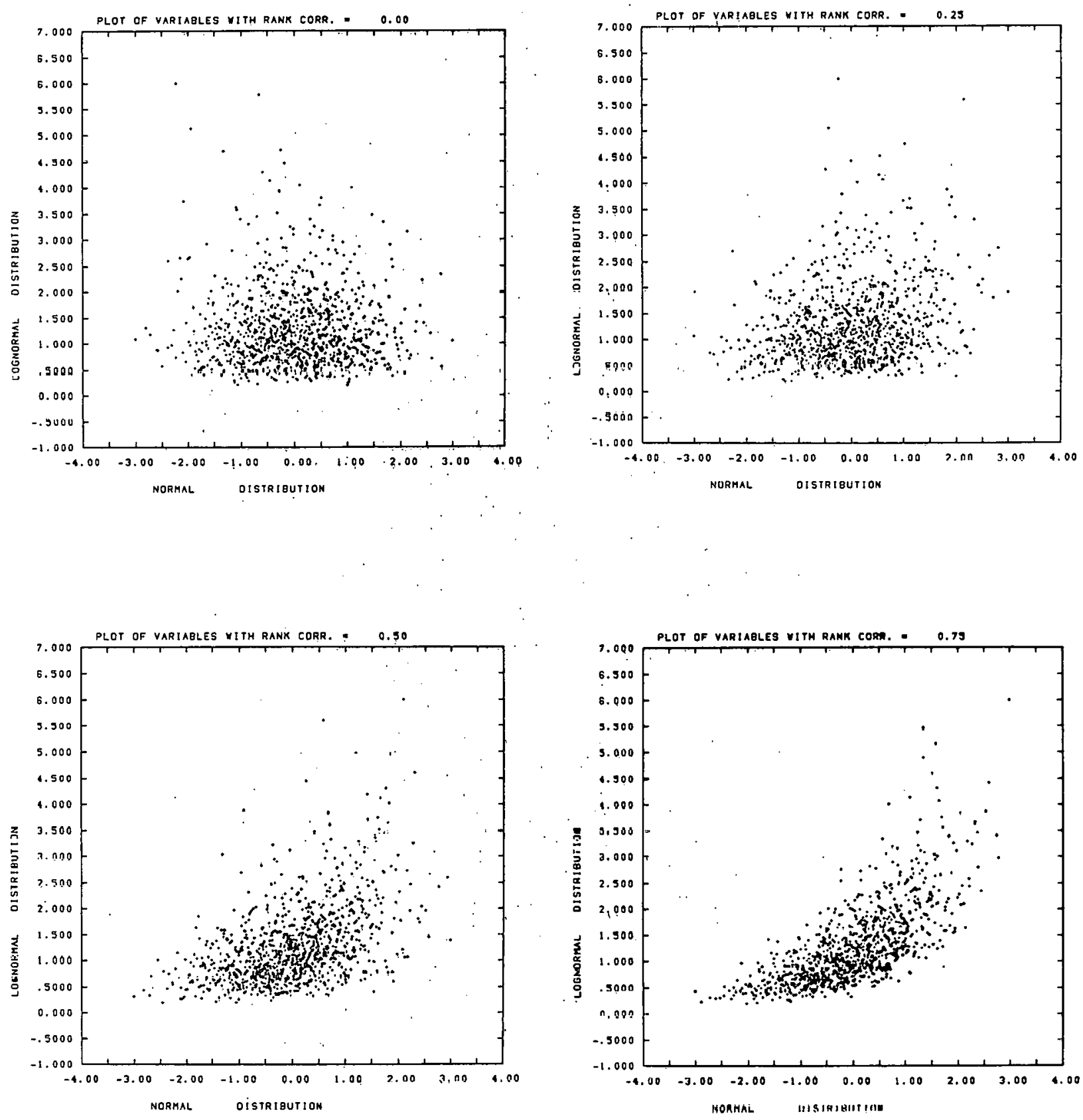

Figure $A-2$

Simulated Scatterplots of "Jointly" Distributed Random Variables with Specified Target Rank Correlations with Sample Size $=1000$. Case 2: Normal Distribution vs. Lognormal Distribution. 

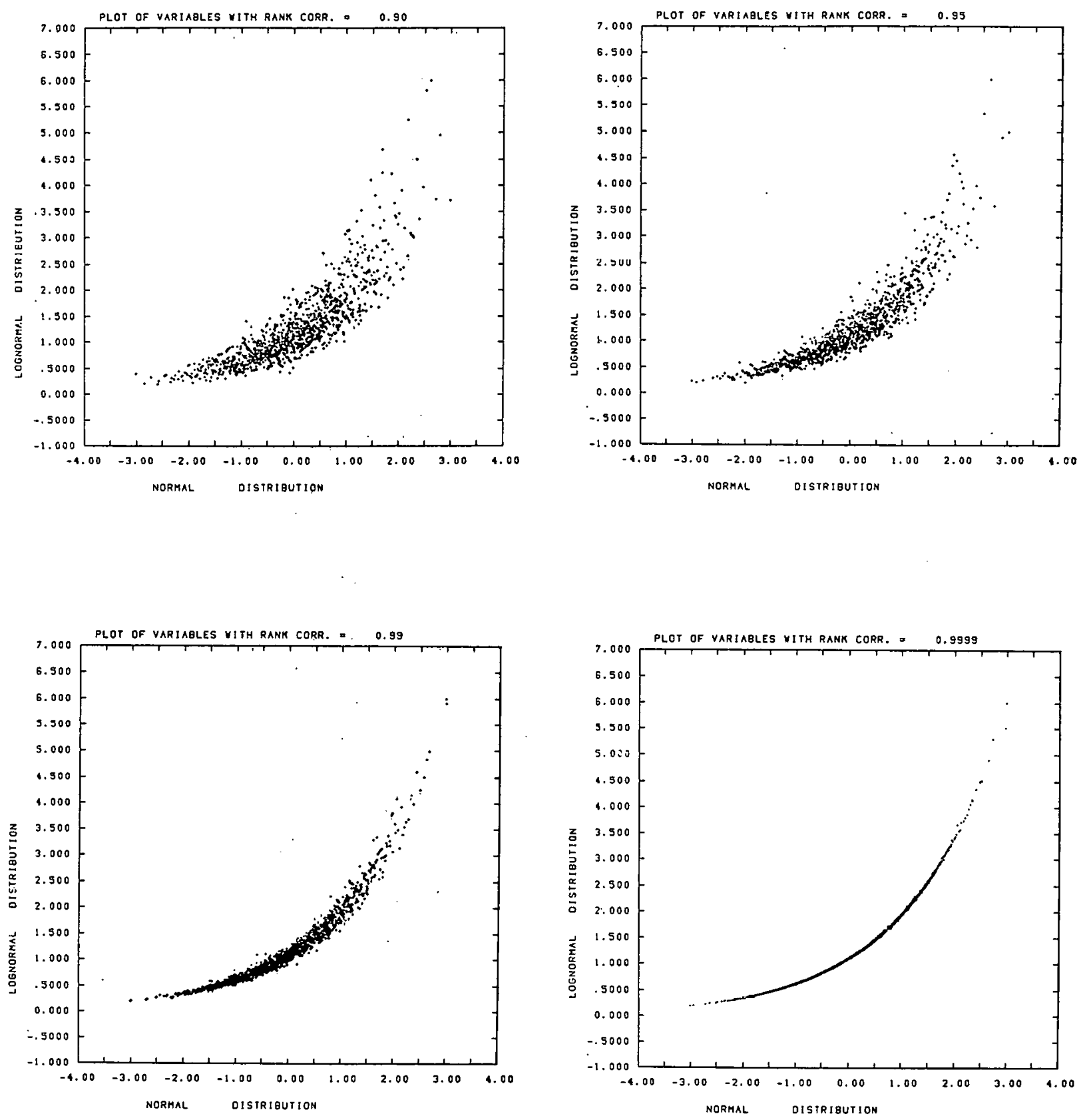

Figure $A-2$

Simulated Scatterplots of "Jointly" Distributed Random Variables with Specified Target Rank Correlations with Sample Size $=1000$. Case 2: Normal Distribution vs. Lognormal Distribution. 

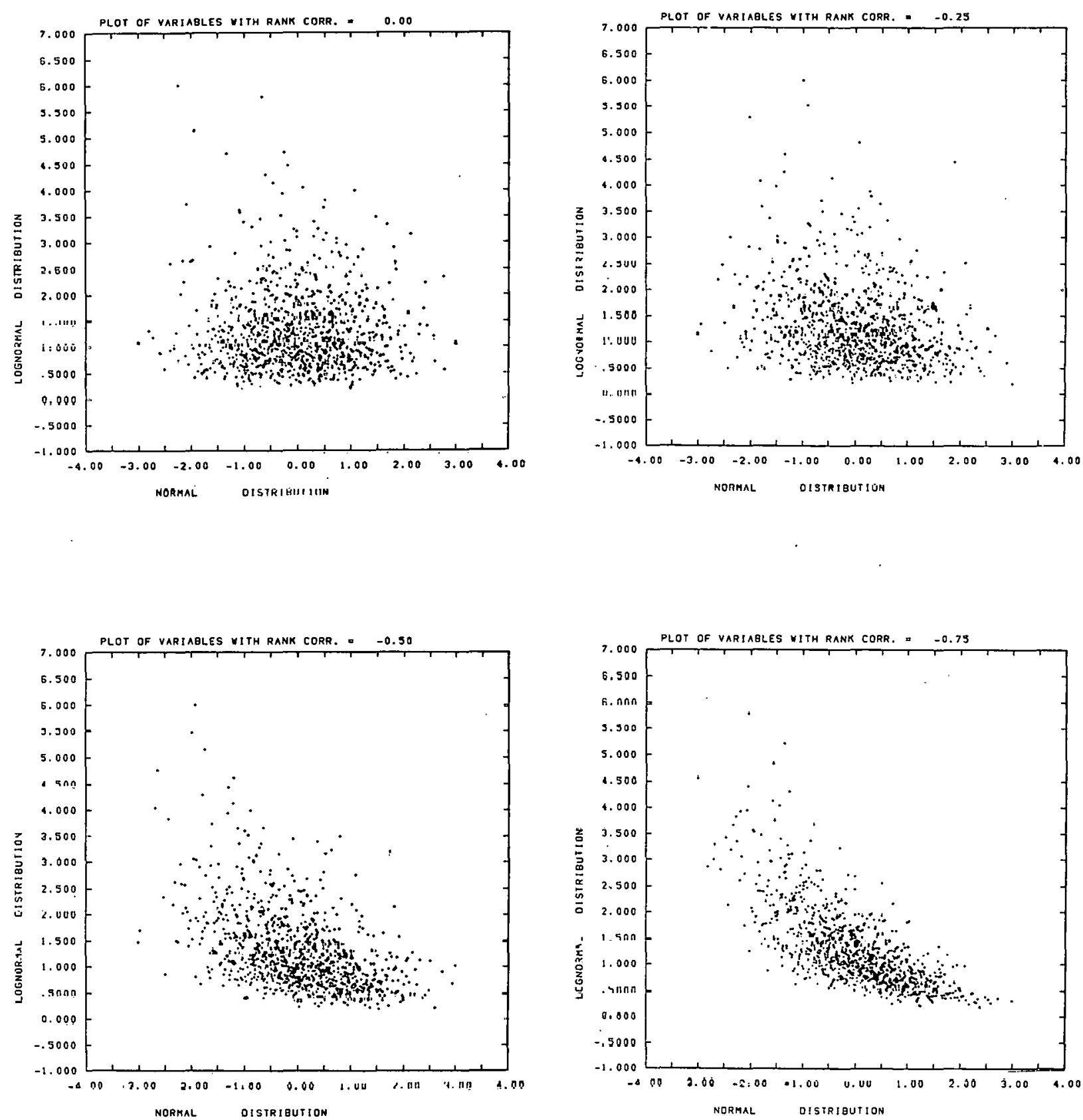

Figure $A-2$

Simulated Scatterplots of "Jointly" Distributed Random Variables with Specified Target Rank Correlations with Sample Size $=1000$. Case 2: Normal Distribution vs. Lognormal Distribution. 

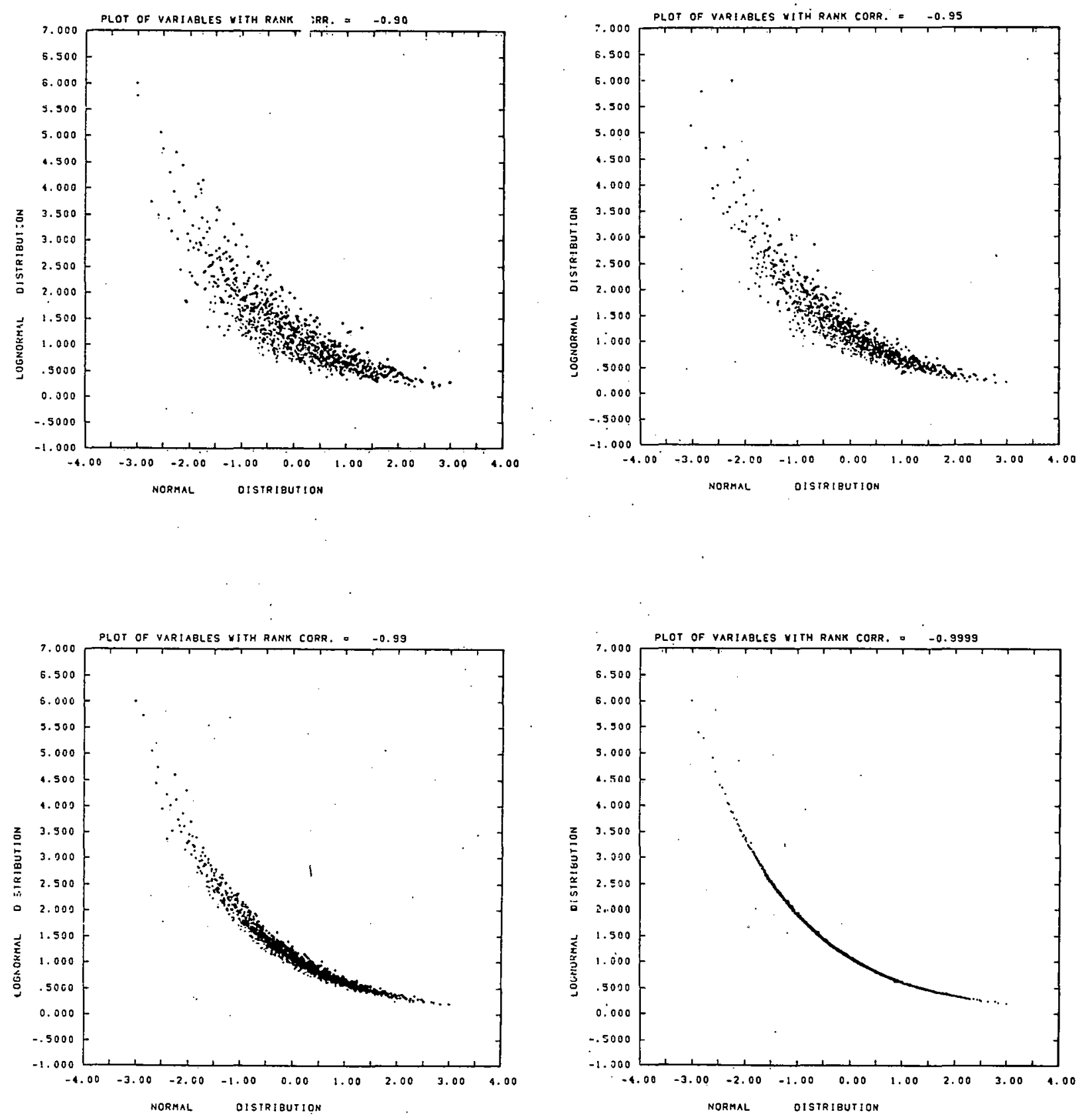

Figure $A-2$

Simulated Scatterplots of "Jointly" Distributed Random Variables with Specified Target Rank Correlations with Sample Size $=1000$. Case 2: Normal Distribution vs. Lognormal Distribution. 

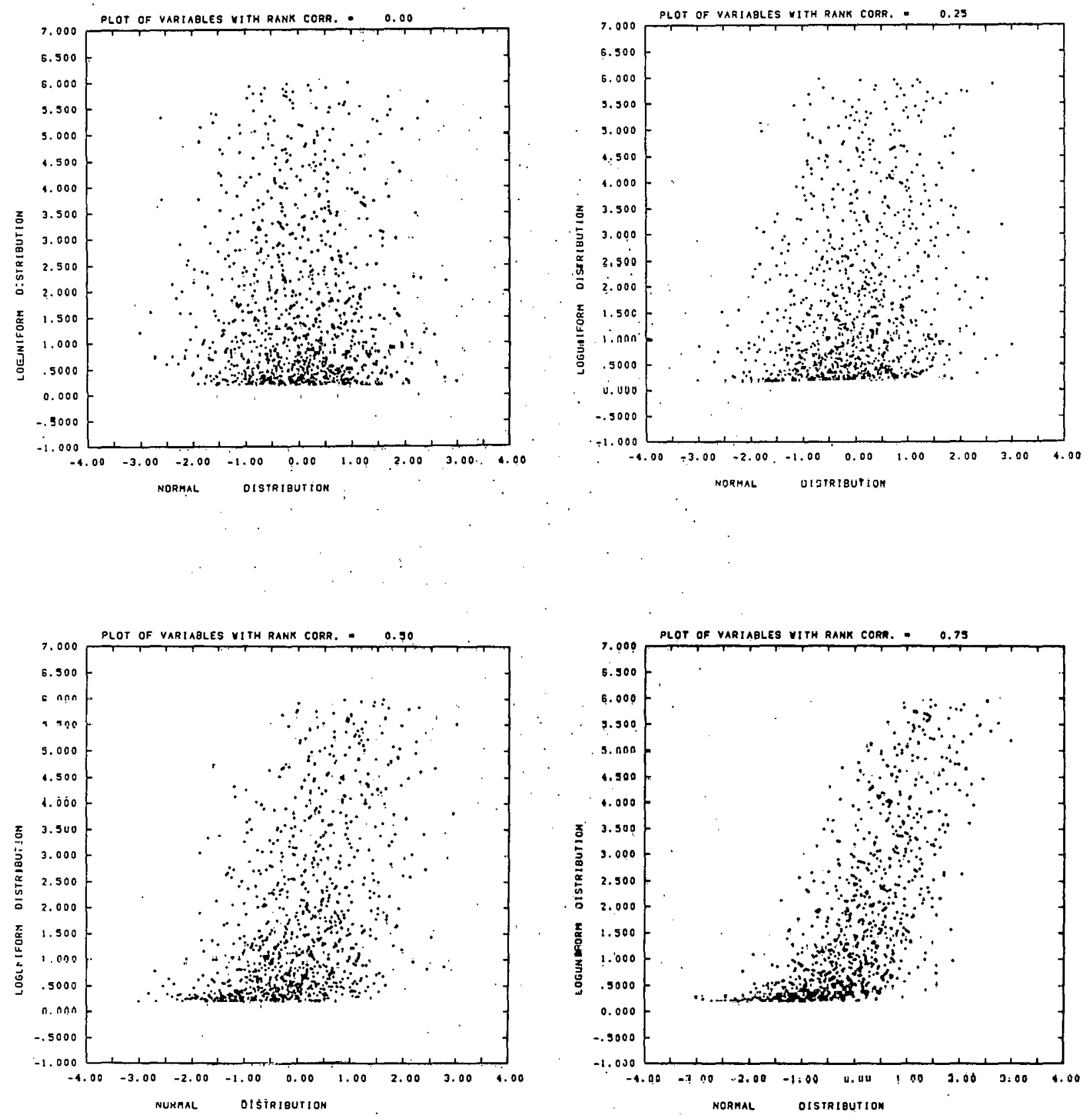

Figure $A-3$

Simulated Scatterplots of "Jointly" Distributed Random Variables with Specified Target Rank Correlations with Sample Size $=1000$. Case 3: Normal Distribution vs. Loguniform Distribution. 

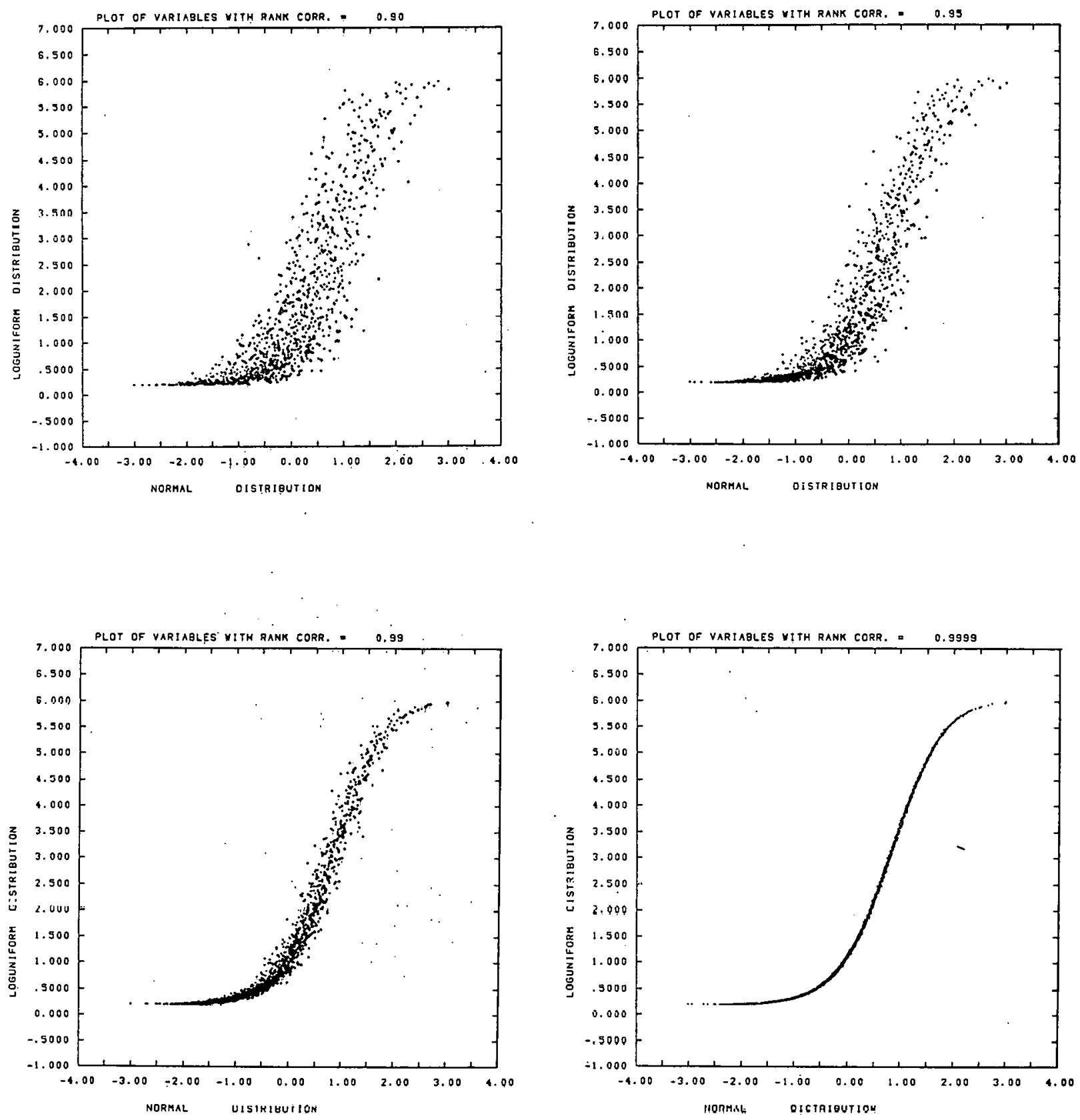

Figure $A-3$

Simulated Scatterplots of "Jointly" Distributed Random Variables with Specified Target Rank Correlations with Sample Size $=1000$. Case 3: Normal Distribution vs. Loguniform Distribution. 

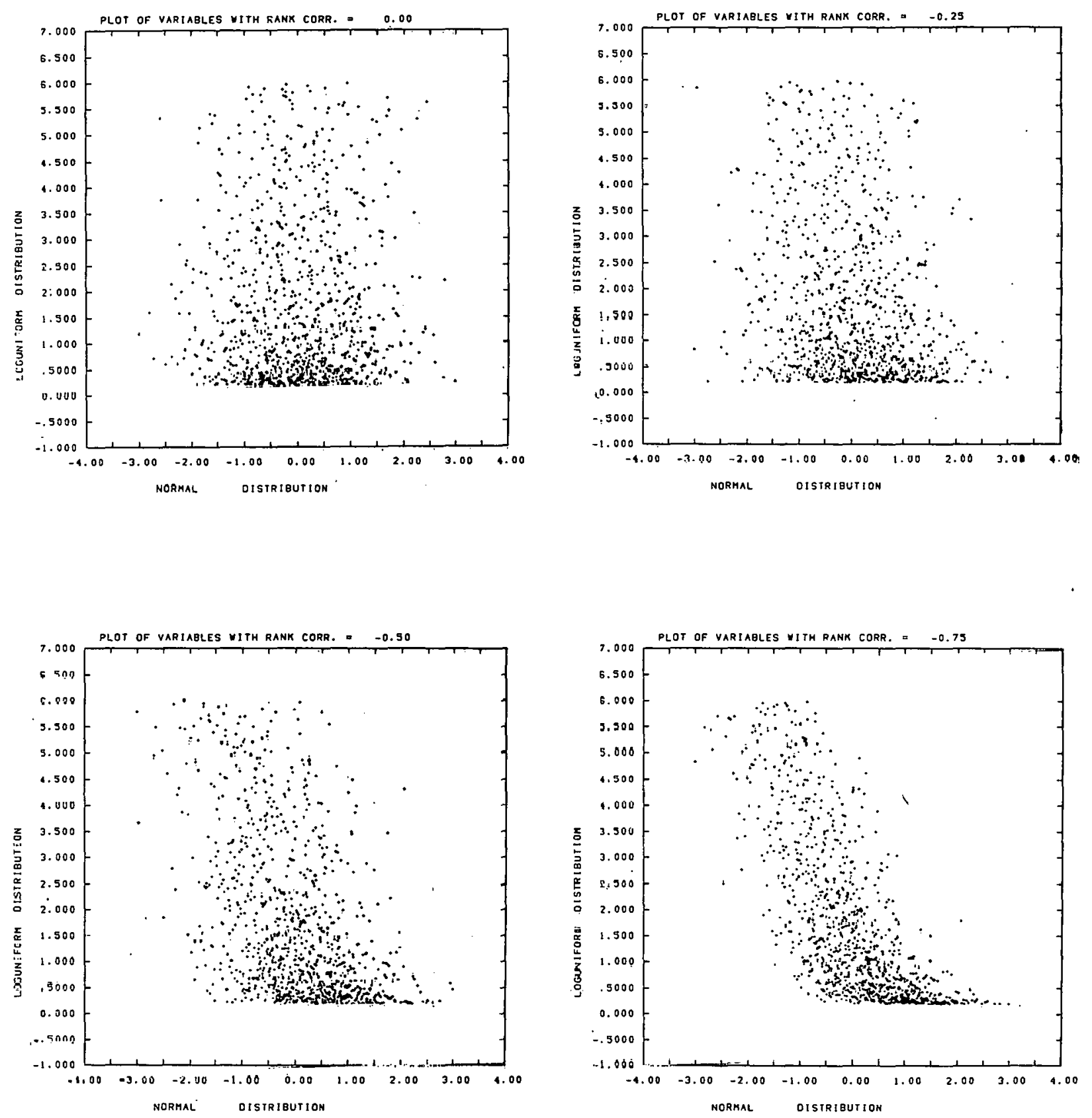

Figure $A-3$

Simulated Scatterplots of "Jointly" Distributed Random Variables with Specified Target Rank Correlations with Sample size $=1000$. Case 3: Normal Distribution vs. Loguniform Distribution. 

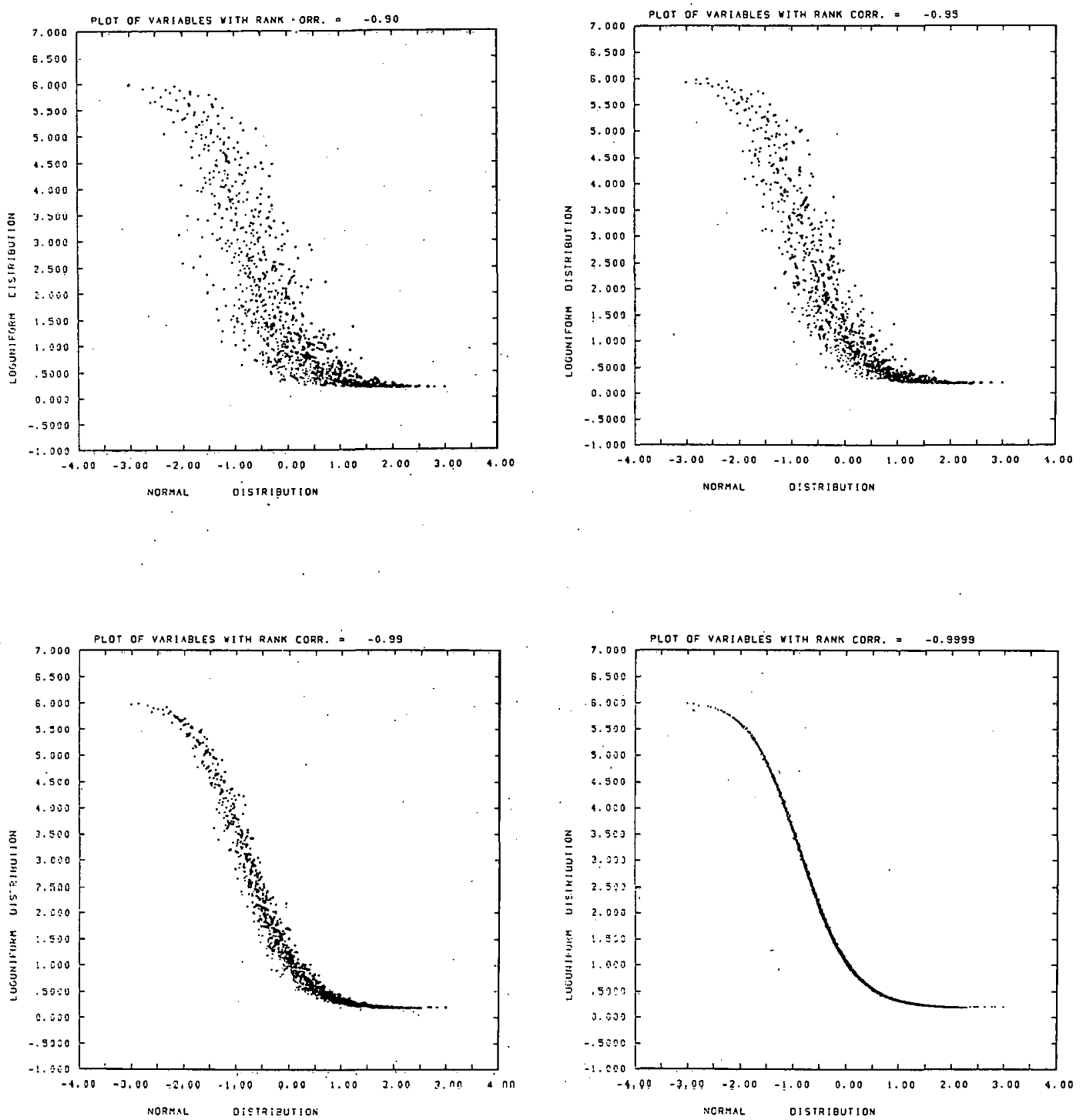

Figure $A-3$

Simulated scatterploțs of "Jointly" Distributed Random Variables with Specified Target Rank Correlations with Sample Size $=1000$. Cace 3: Normal Distribution vs, Loguniform Distribution. 

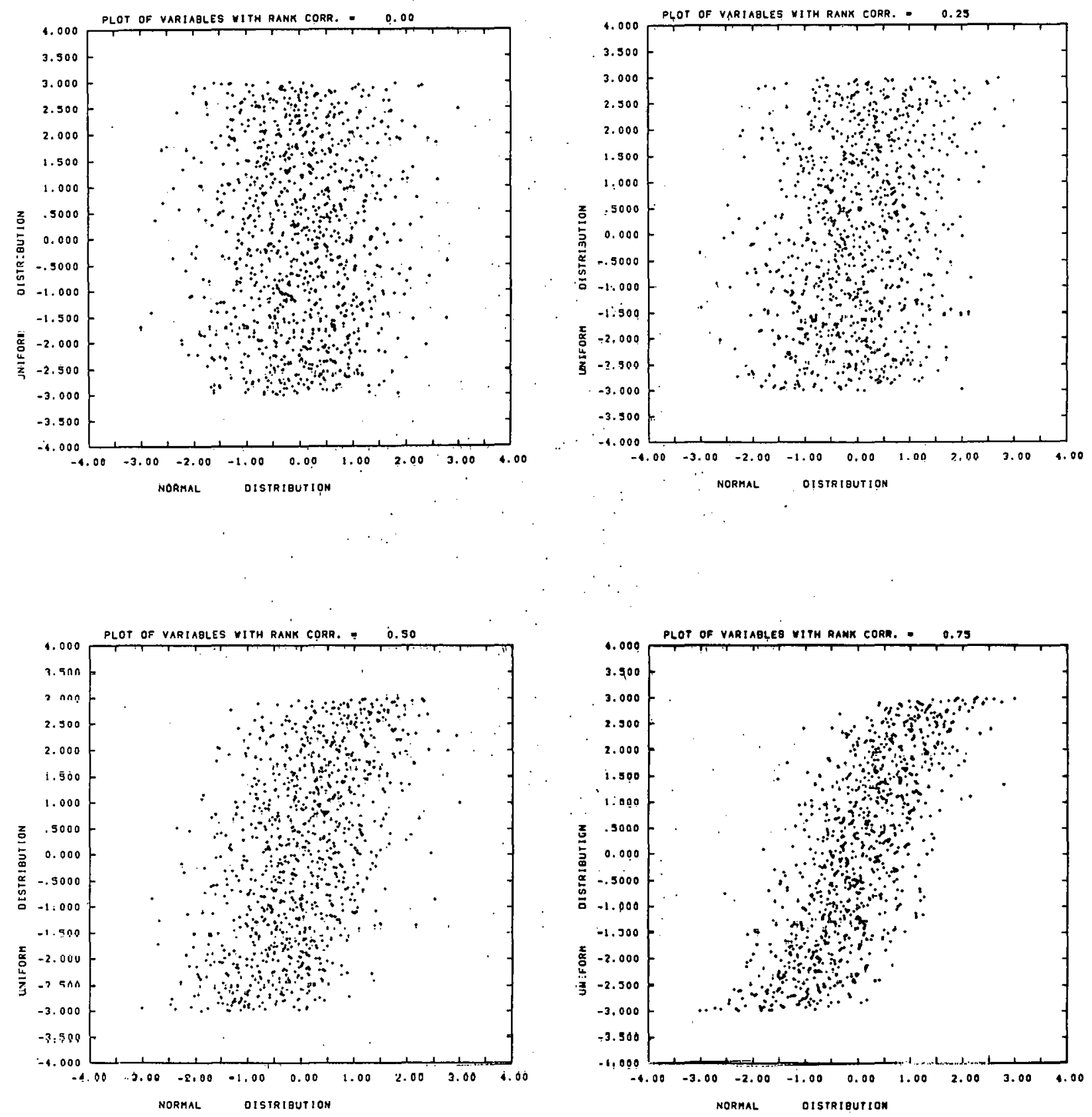

Fịgure $A=1$

Simulated Scatterplots of "Jointly" Distributed Random Variables with Specified Target Tank Correlations with Sample Size $=1000$. Case 4: Normal Distribution vs. Uniform Distribution. 

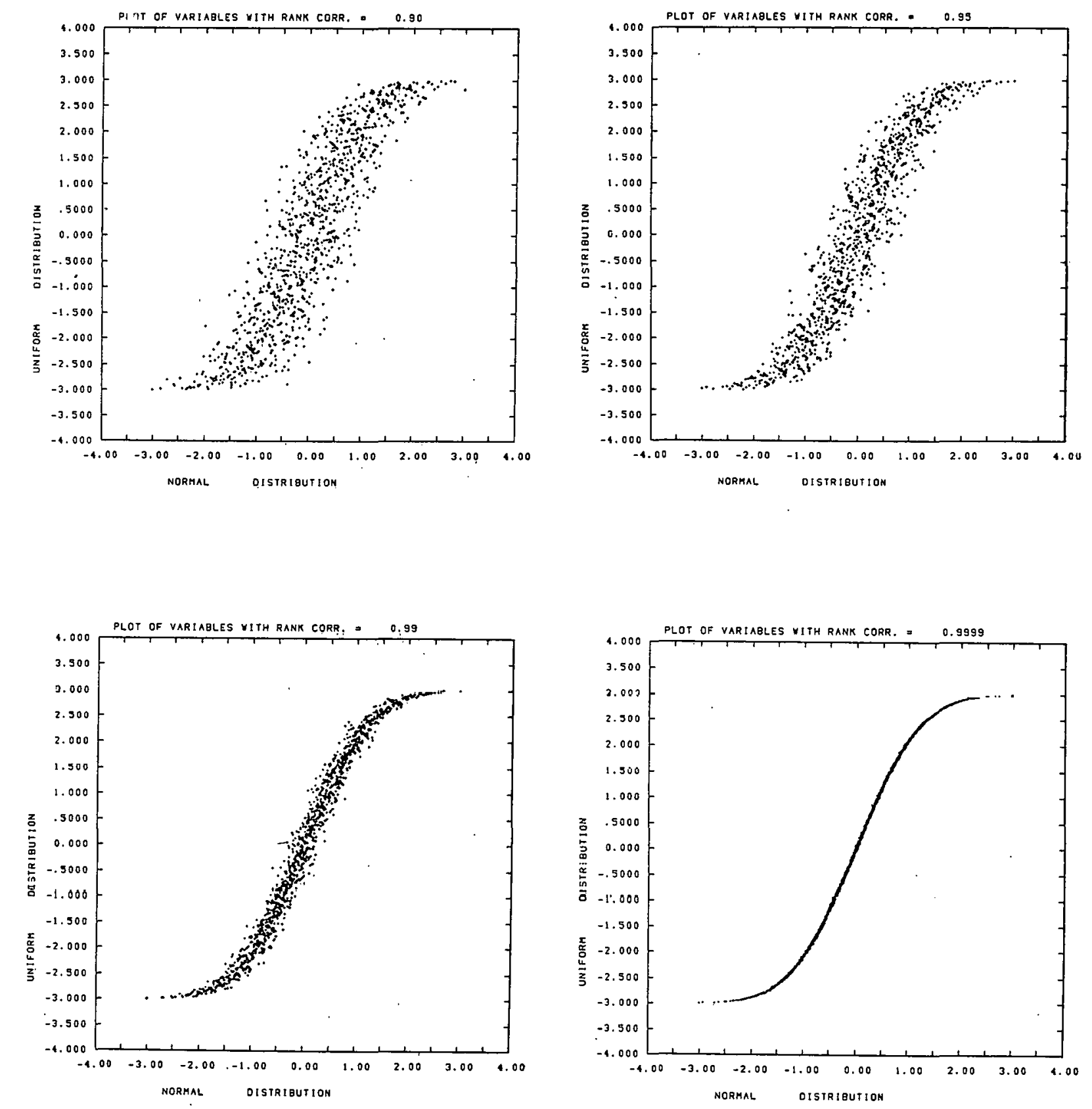

Figure $A-4$

Simulated Scatterplots of "Jointly" Distributed Random Variables with Specified Target Rank Correlations with Sample Size $=1000$. Case 4: Normal Distribution vs. Uniform Distribution. 

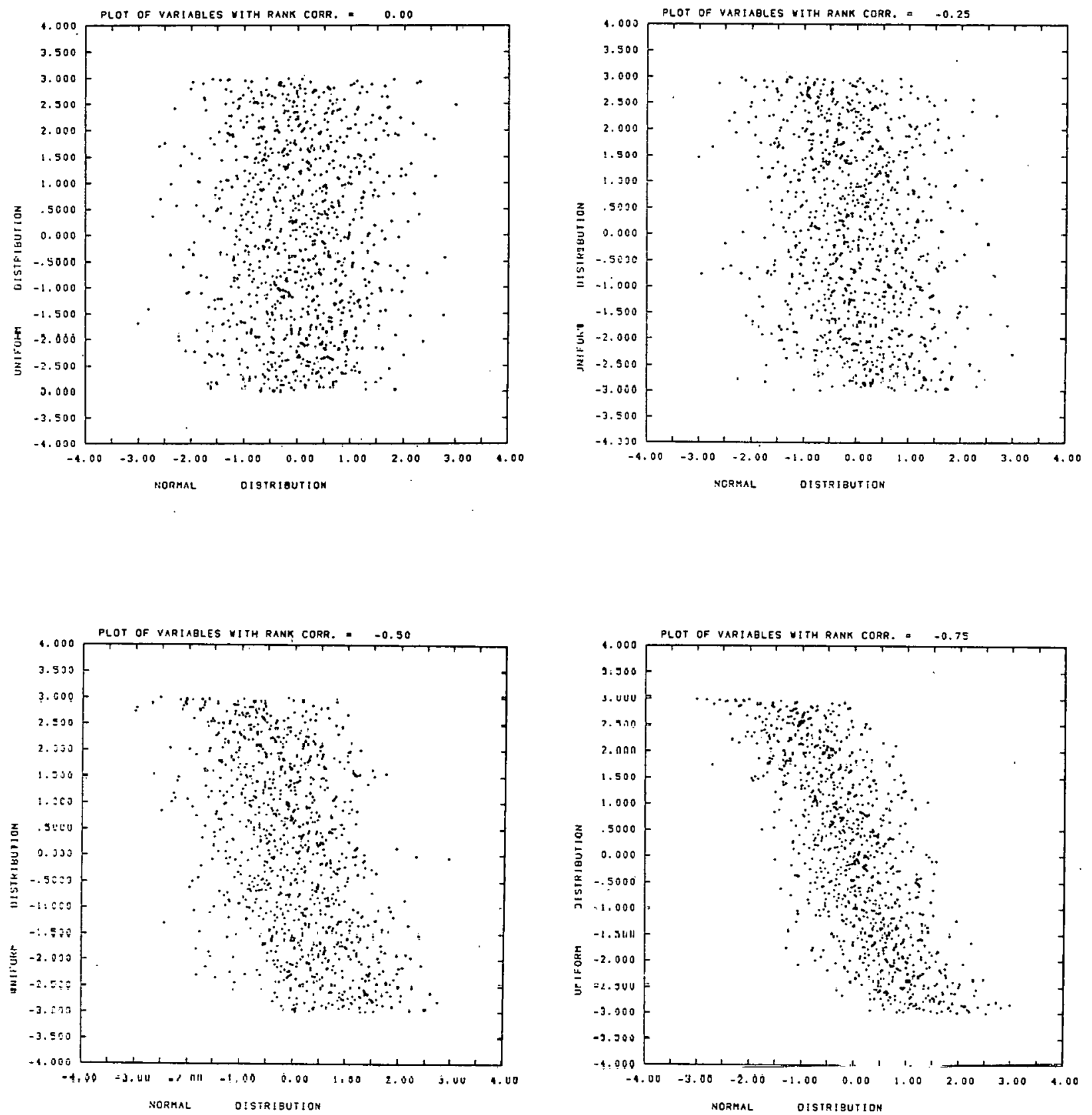

Figure $A-4$

Simulated Scatterplots of "Jointly" Distributed Random Variables with Specified Target Rank Correlations with Sample Size $=1000$. Case 4: Normal Distribution vs. Uniform Distribution. 

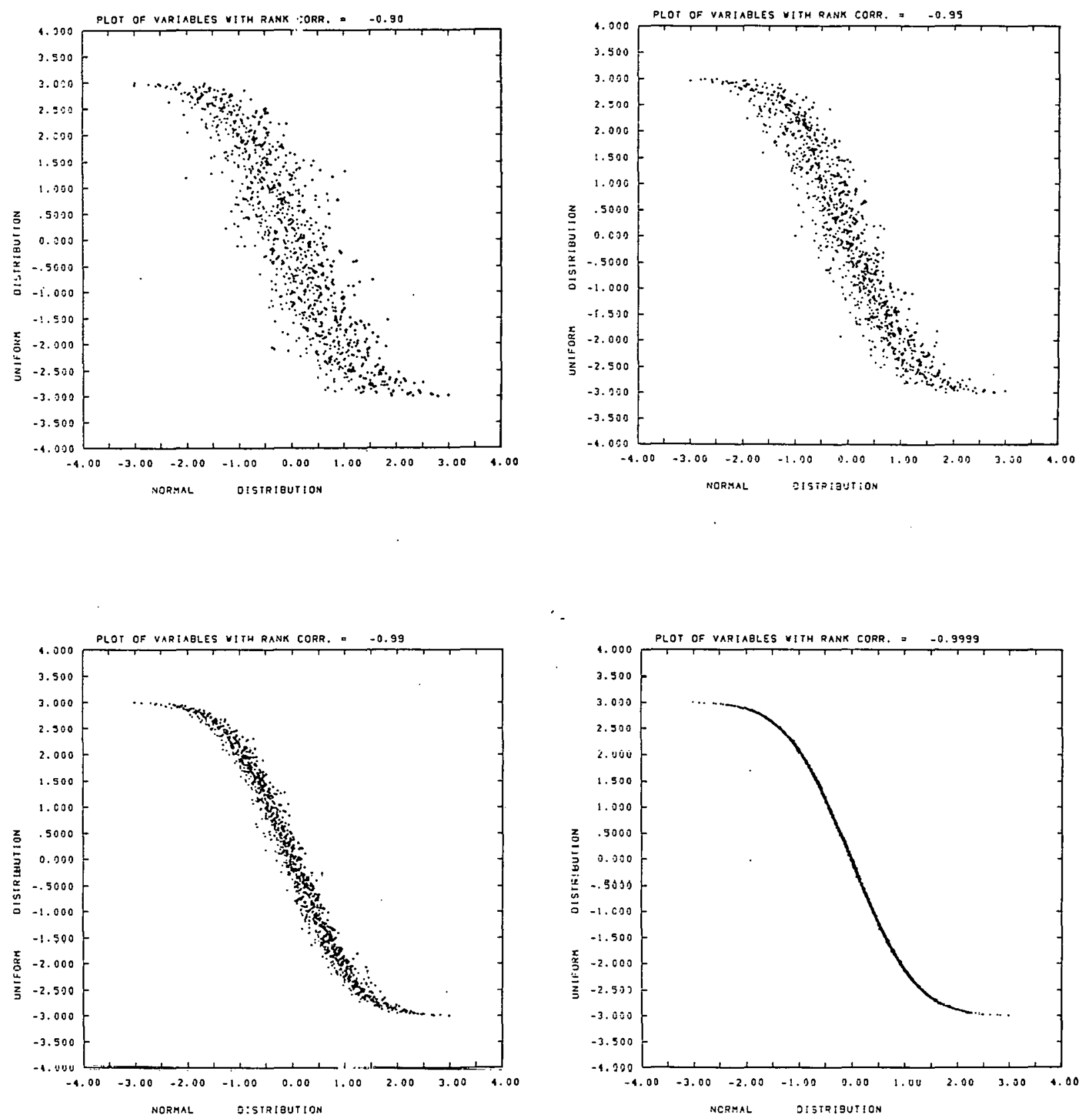

Figure $A-4$

Simulated Scatterplots of "Jointly" Distributed Random Variables with Specified Target Rank Correlations with Sample Size $=1000$. case 4: Nnrmal Distribution vs. Uniform Distribution. 

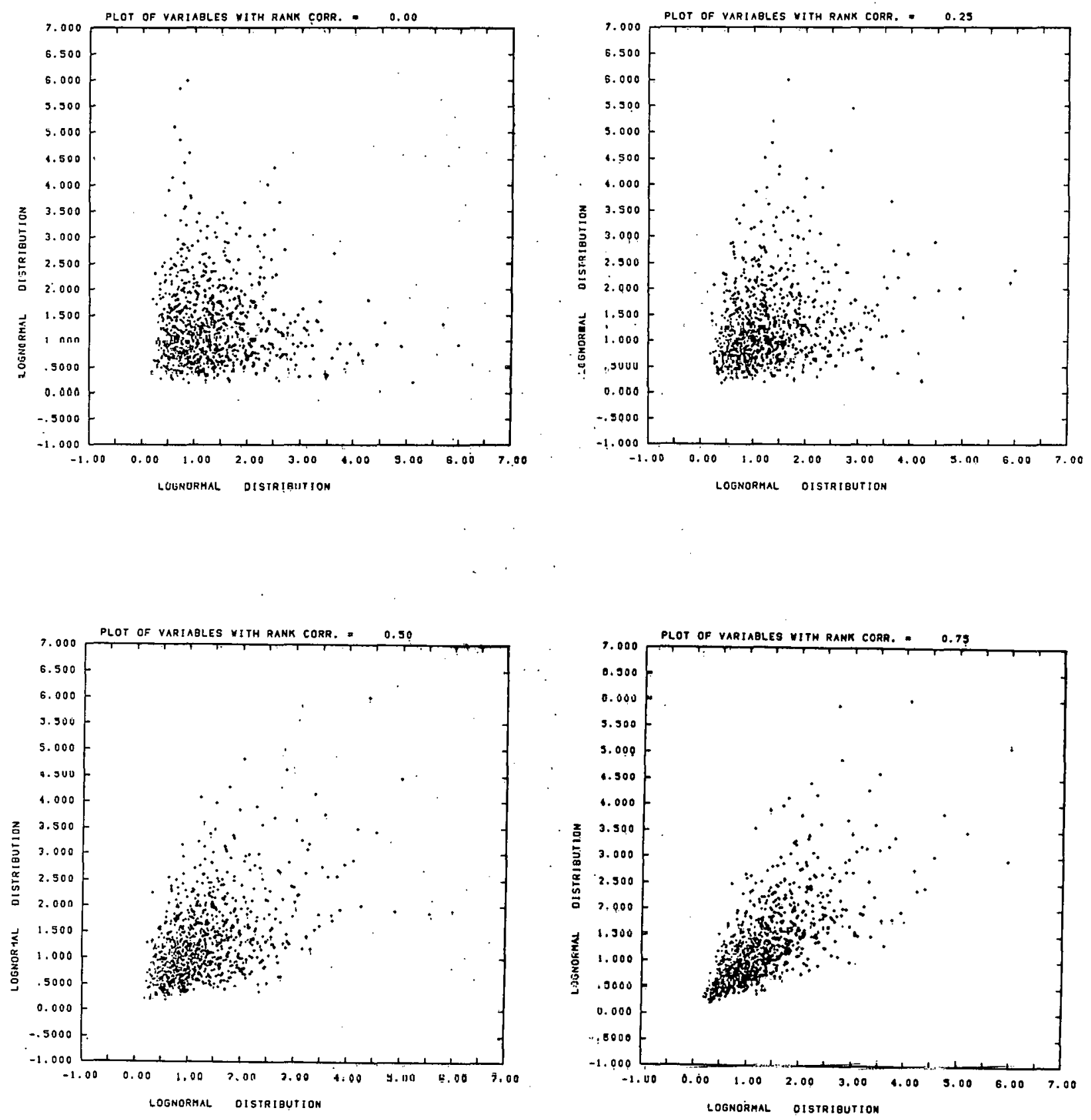

Figure $A-5$

Simulated Scatterplots of "Jointly" Distributed Random Variables with Specified Target Rank Correlations with Sample Size $=1000$. Case 5: Lognormal Distribution vs. Lognormal Distribution. 

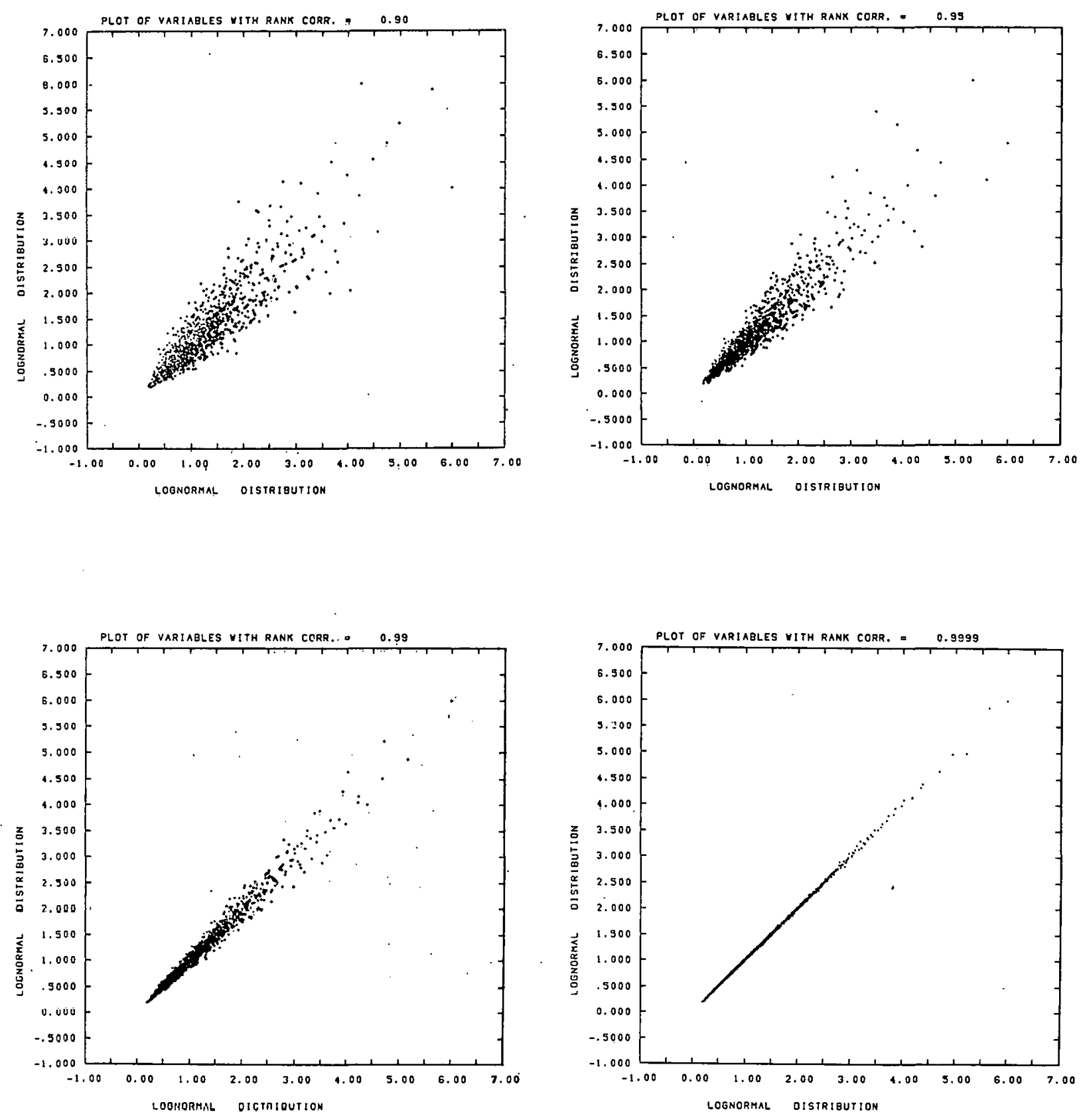

Figure $A-5$

Simulated Scatterplots of "Jointly" Distributed Random Variables with Specified Target Rank Correlations with Sample Size $=1000$. Case 5: Lognormal Distribution vs. Lognormal Distribution. 

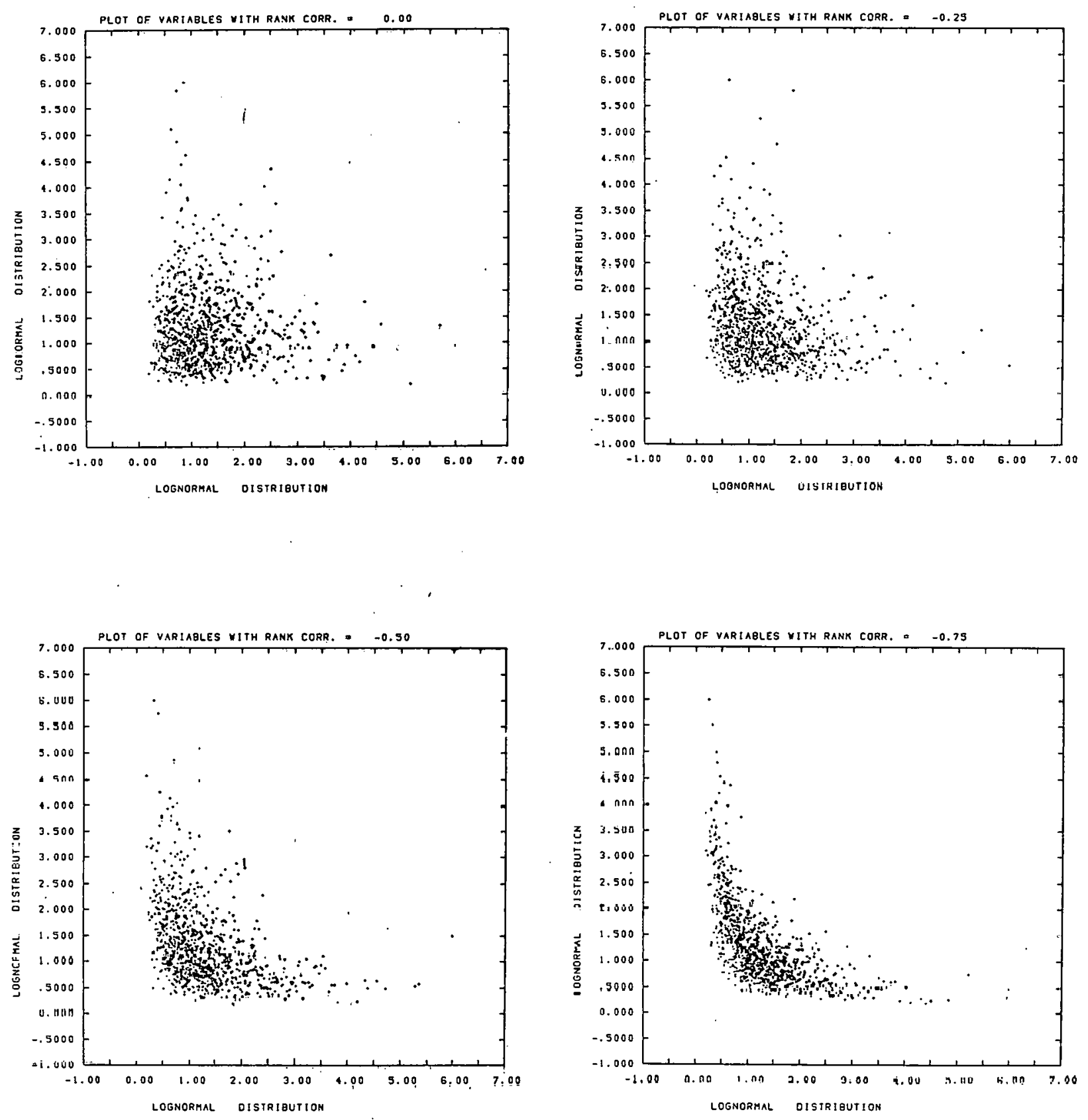

Figure $A-5$

Simulated Scatterplots of "Jointly" Distributed Random Variables with Specified Target Rank Correlations with Sample Size $=1000$. Case 5: Lognormal Distribution vs. Lognormal Distribution. 

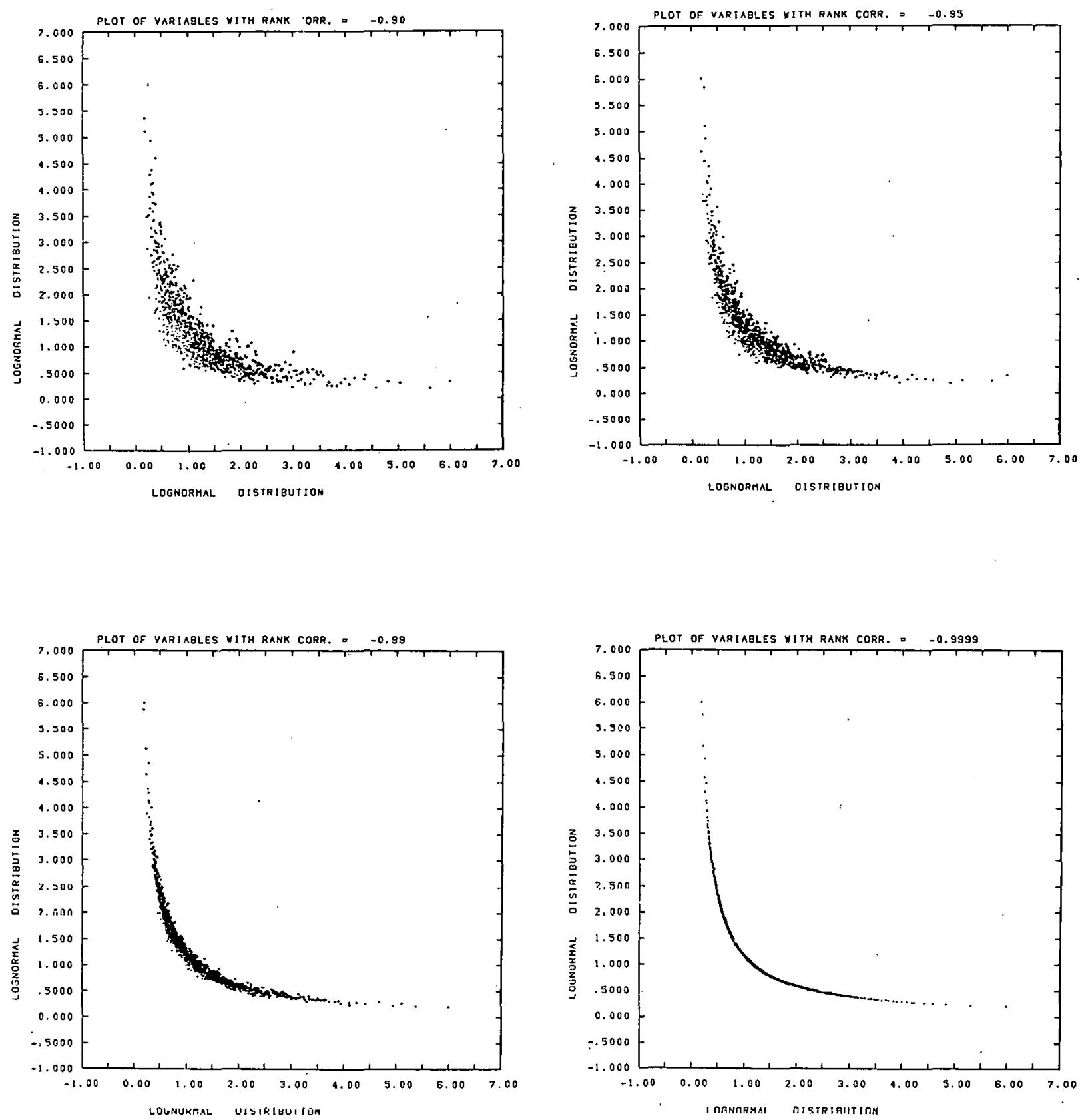

Figure $A-5$

Simulated Scatterplots of "Jointly" Distributed Random Variables with Specified Target Rank Correlations with Sample Size $=1000$. Case 5: Lognormal Distribution vs. Lognormal Distribution. 

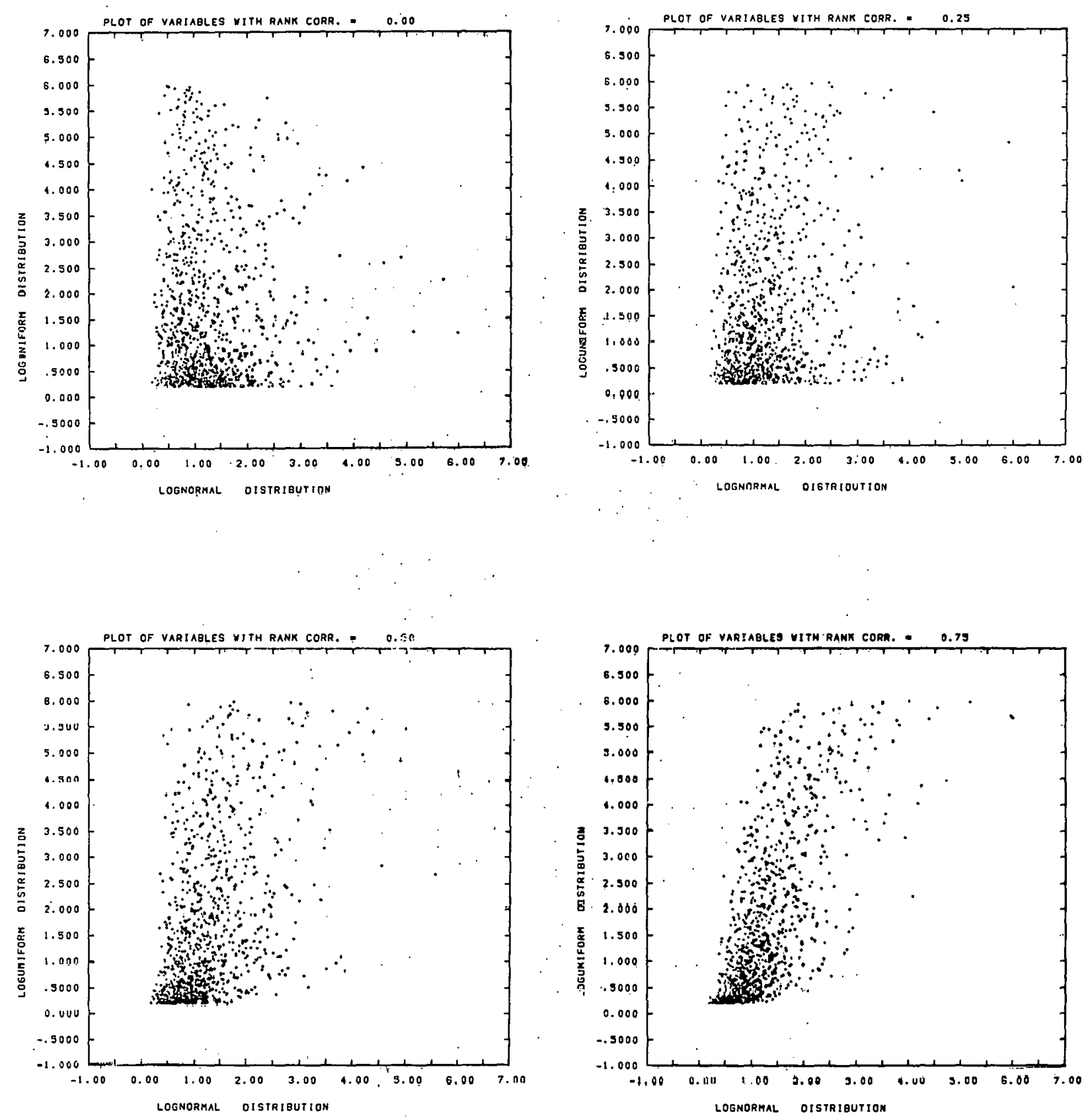

Figure $A-6$

Simulated Scatterplots of "Jointly" Distributed Random Variables with specified Target Rank Correlations with Sample size $=1000$. case 6: Lognormal Distribution $\mathrm{ys}$. Loguniform Distribution. 

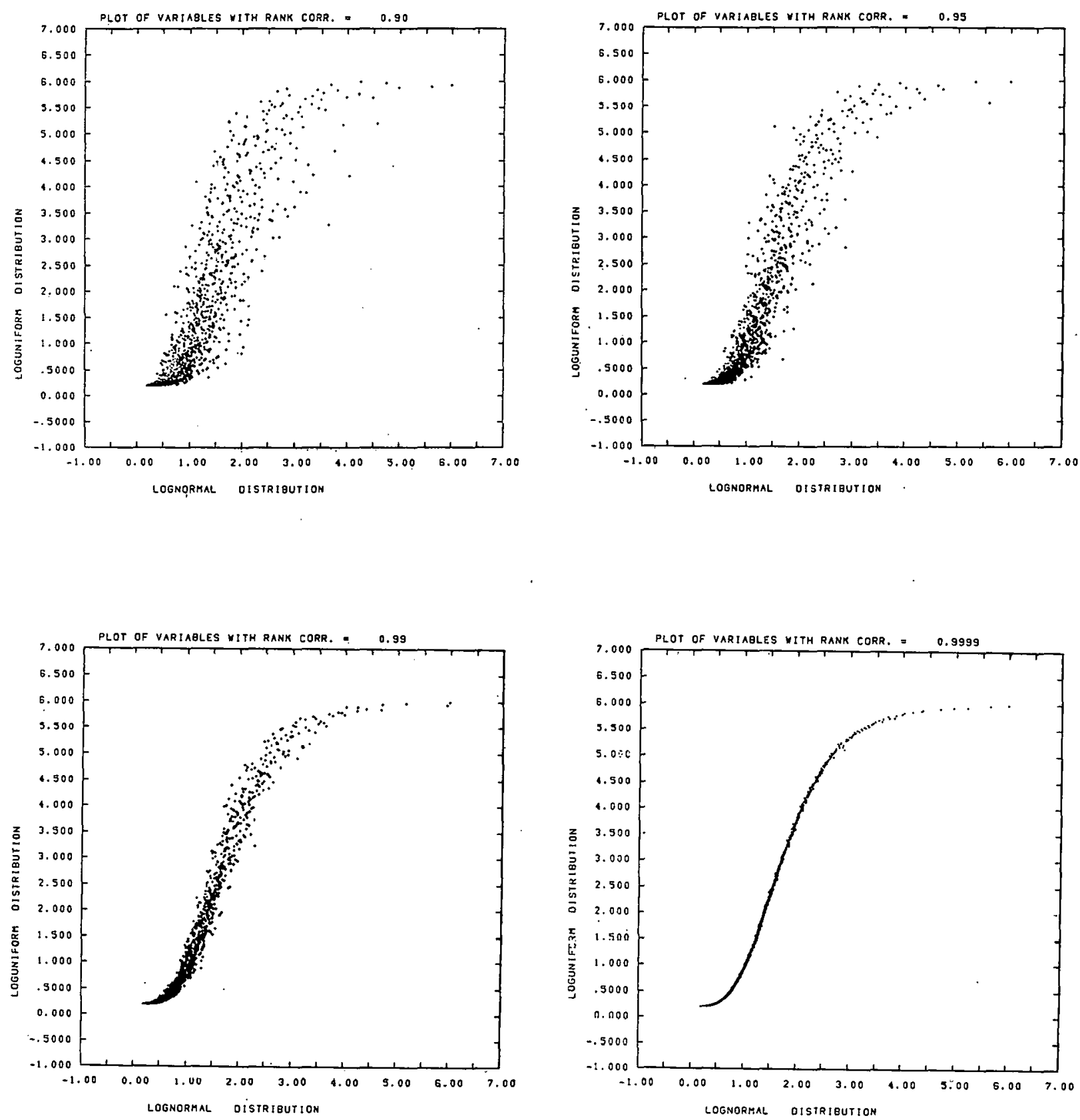

Figure $A-6$

Simulated Scatterplots of "Jointly" Distributed Random Variables with Specified Target Rank Correlations with Sample Size $=1000$. Case 6: Lognormal Distribution vs. Loguniform Distribution. 

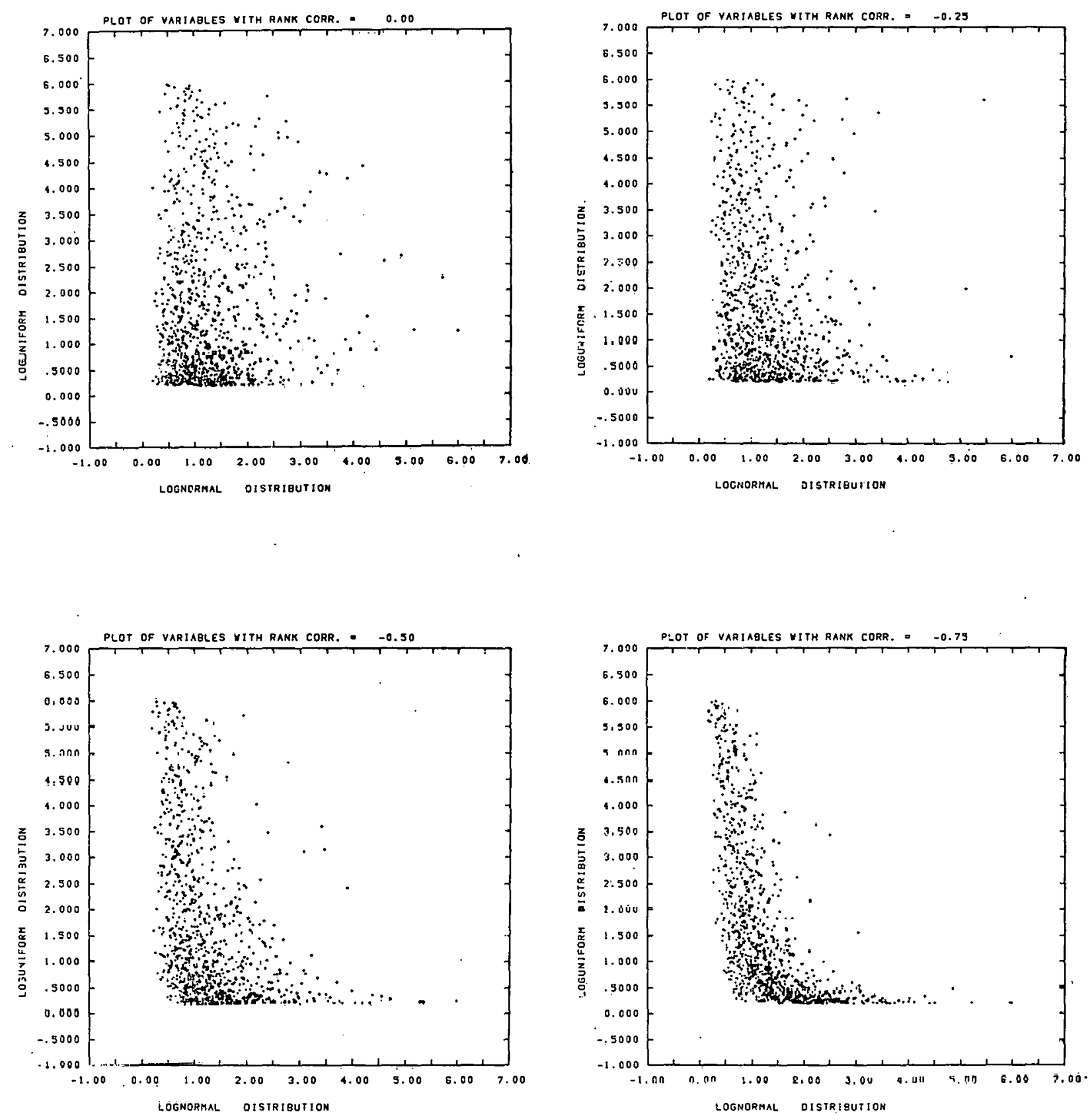

Figure $A-6$

simulated Scatterplots of "Jointly" Distributed Random Variables with Specified Target Rank Correlations with Sample Size $=1000$. Case 6: Lognormal Distribution vs. Loguniform Distribution. 

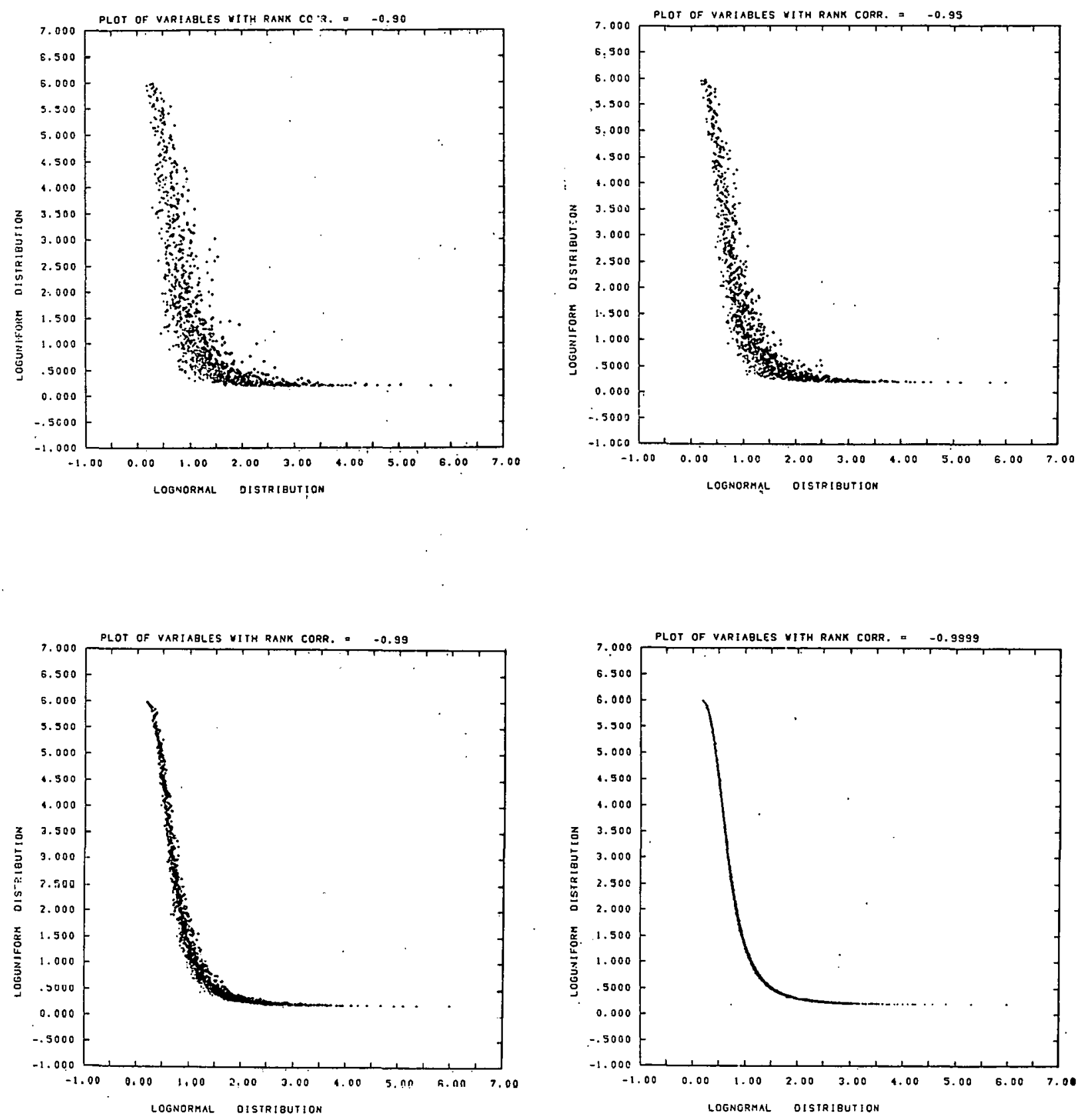

Figure $A-6$

Simulated Scatterplots of "Jointly" Distributed Random Variables with Specified Target Rank Correlations with Sample Size $=1000$.

case $6:$ Lognormal Distribution vs. Luyunifun Dislitilition. 

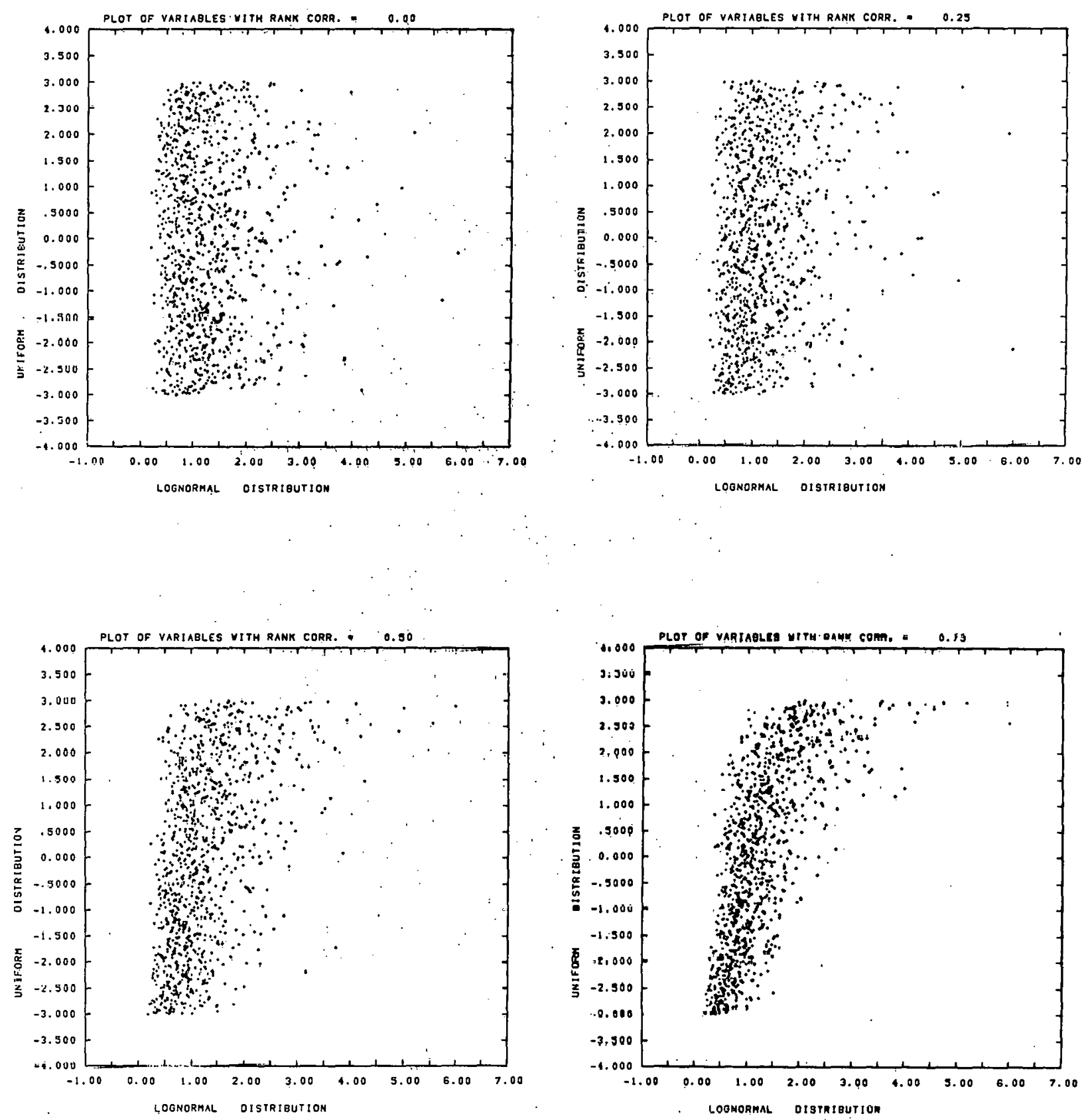

Figure $\mathrm{A}-7$

Simulated Scatterplots of "Jointly" Distributed Random Variables with Specified Target Rank Correlations with Sample Size $=1000$. case 7: Lognormal Distribution vs. Uniform Distribution. 

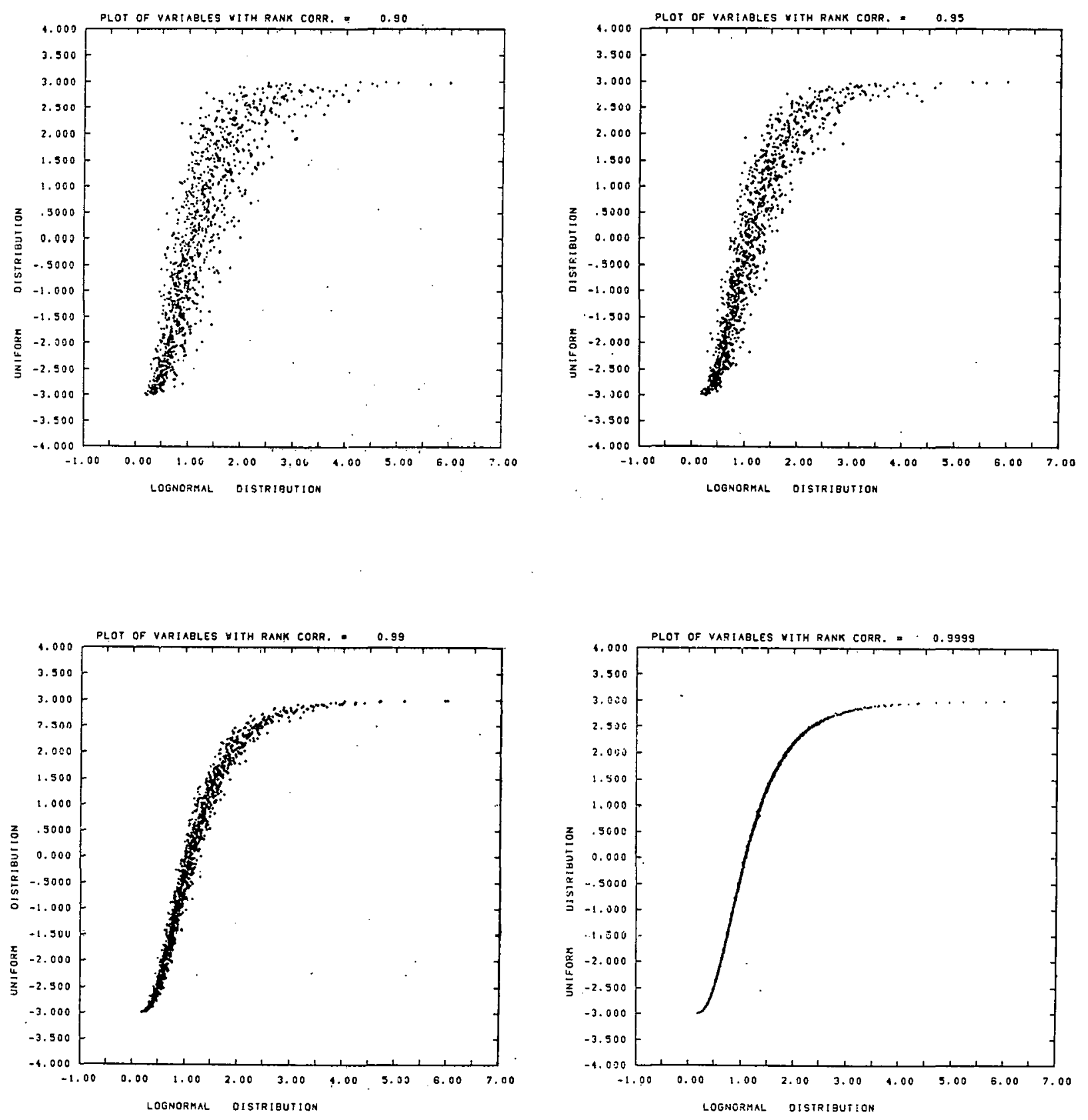

Figure $A-7$

Simulated Scatterplots of "Jointly" Distributed Random Variables with Specified Target Rank Correlations with Sample Size $=1000$. Case 7: Lognormal Distribution vs. Uniform Distribution. 

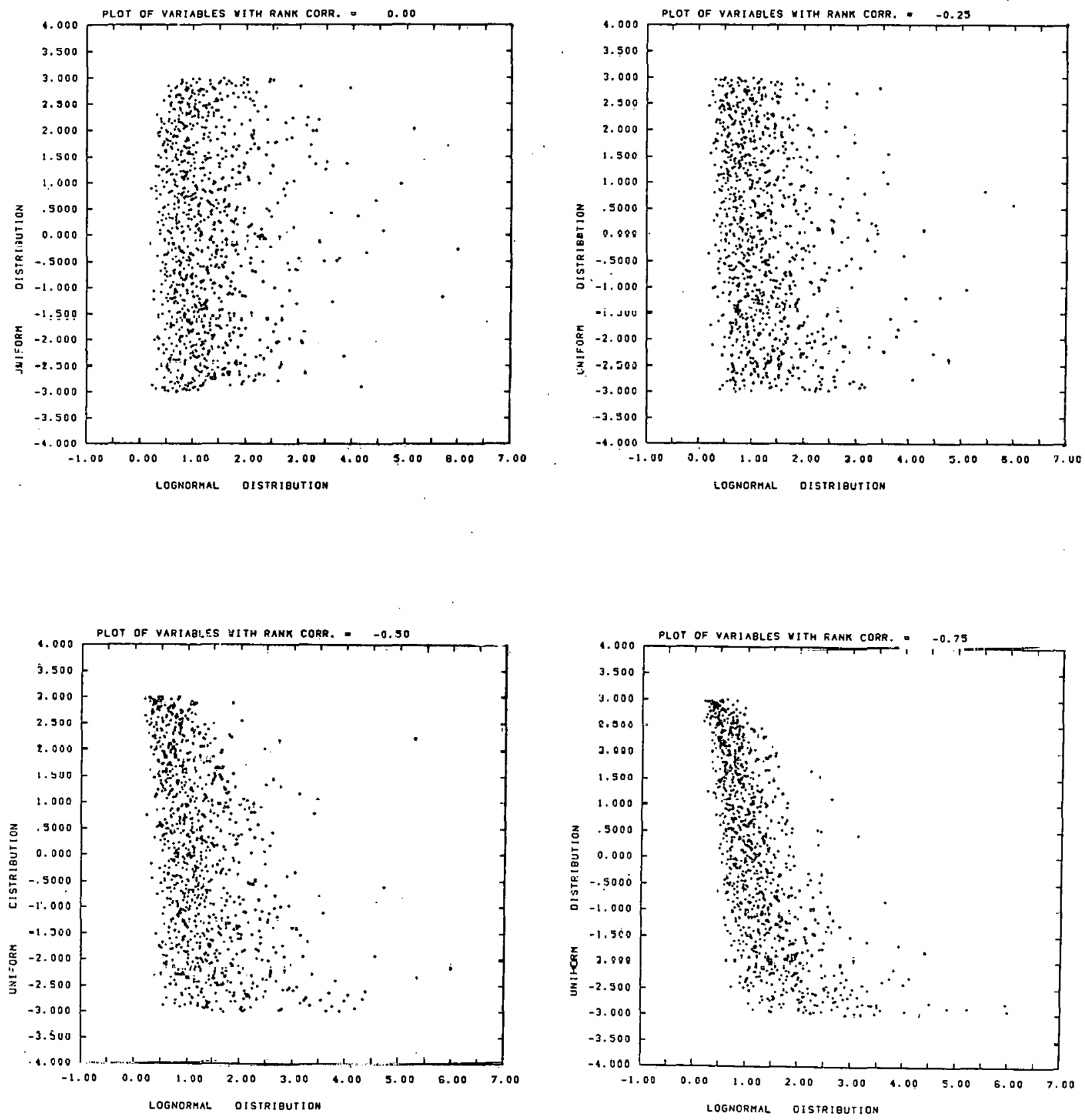

Figure $A-7$

Simulated Scatterplots of "Jointly" Distributed Random Variables with Specified Target Rank Correlations with Sample Size $=1000$. Case 7: Lognormal Distribution vs. Uniform Distribution. 

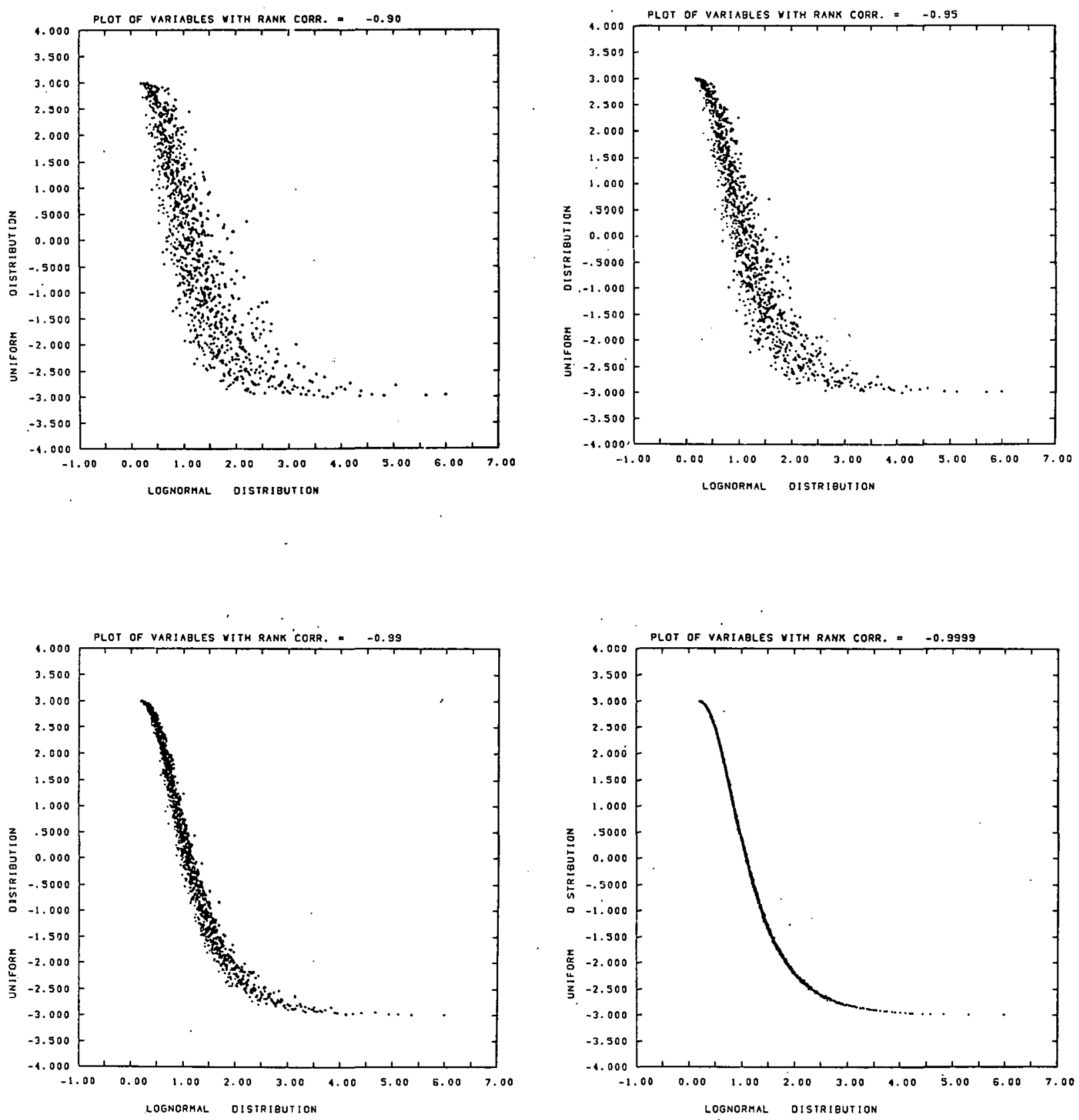

Simulated Scatterplots or "Jointly" Distributed Random Variables with Specified Target Rank Correlations with Sample Size $=1000$. Case 7: Lognormal Distribution vs. Uniform Distribution. 

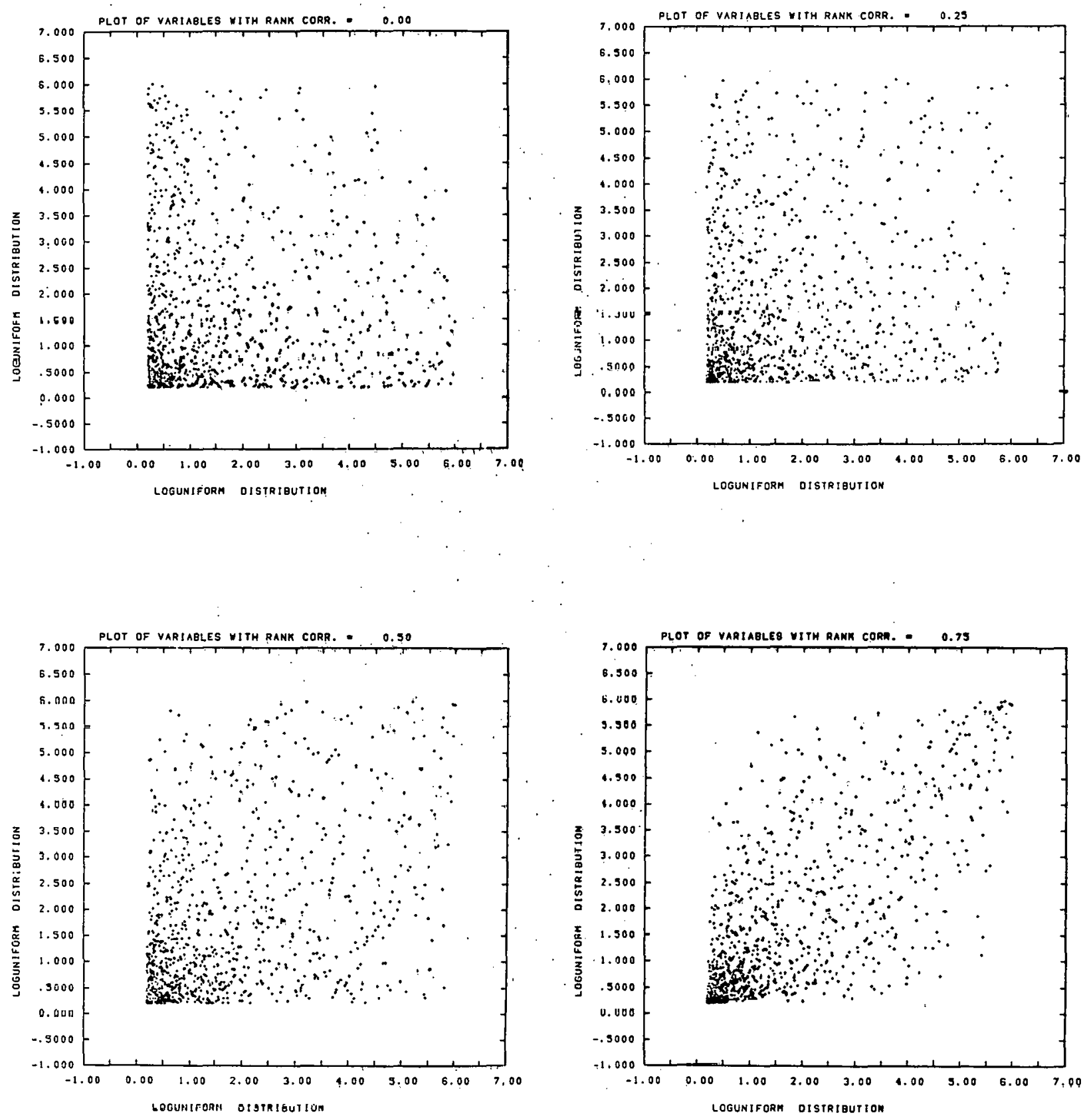

Fiqure $A-8$

Simulated Scatterplots of "Jointly" Distributed Random Variables with Specified Target Rank Correlations with Sample Size $=1000$. Case 8: Loguniform Distribution vs. Loguniform Distribution. 



Figure $A-8$

Simulated Scatterplots of "Jointly" Distributed Random Variables with Specified Target Rank Correlations with Sample Size $=1000$.

Case 8: Loguniform Distribution vs. Loguniform Distribution. 

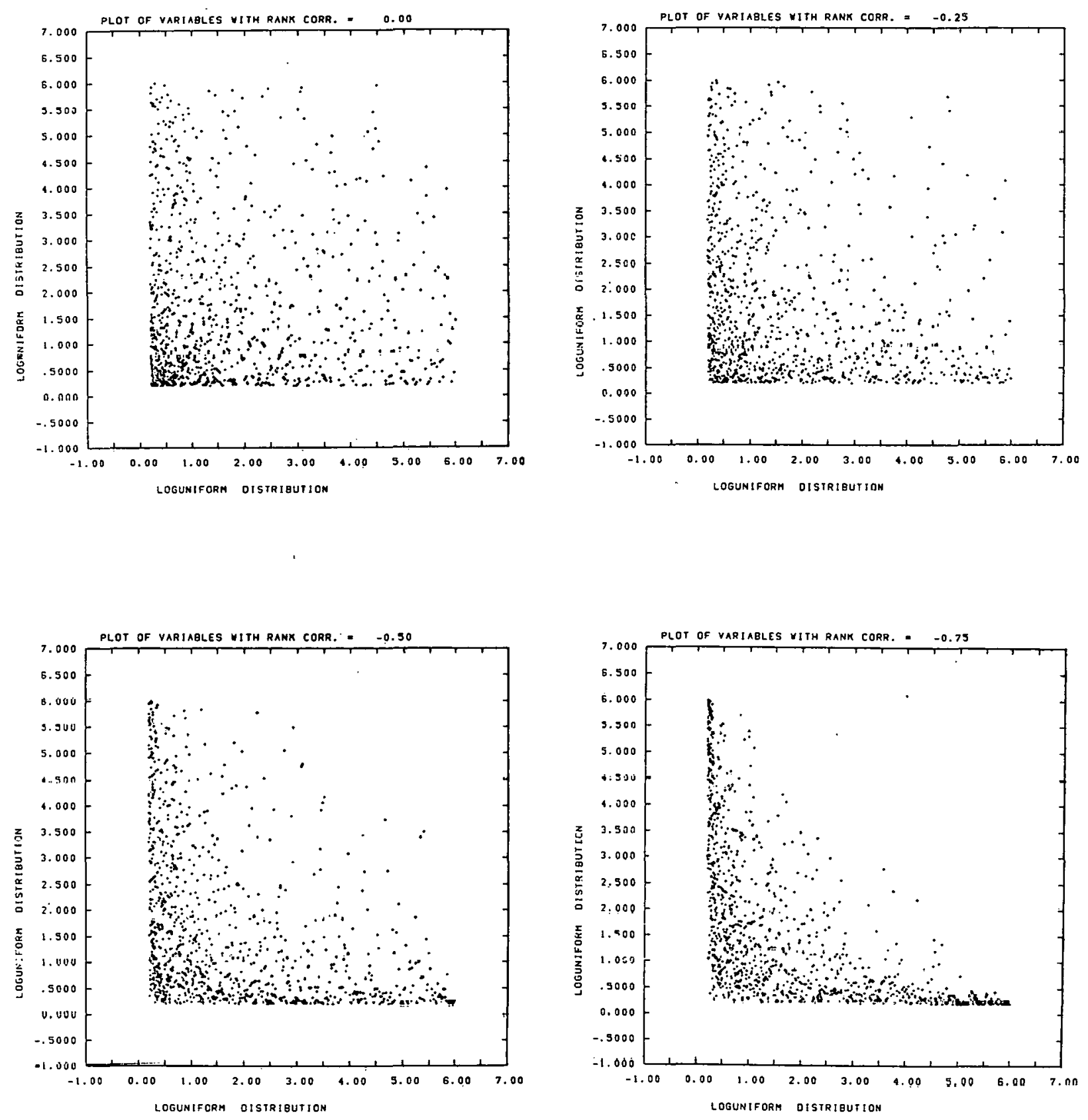

Figure $A-8$

Simulated Scatterplots of "Jointly" Distributed Random Variables with Specified Target Rank Correlations with Sample Size $=1.000$. Case 8: Loguniform Distribution vs. Loguniform Distribution. 

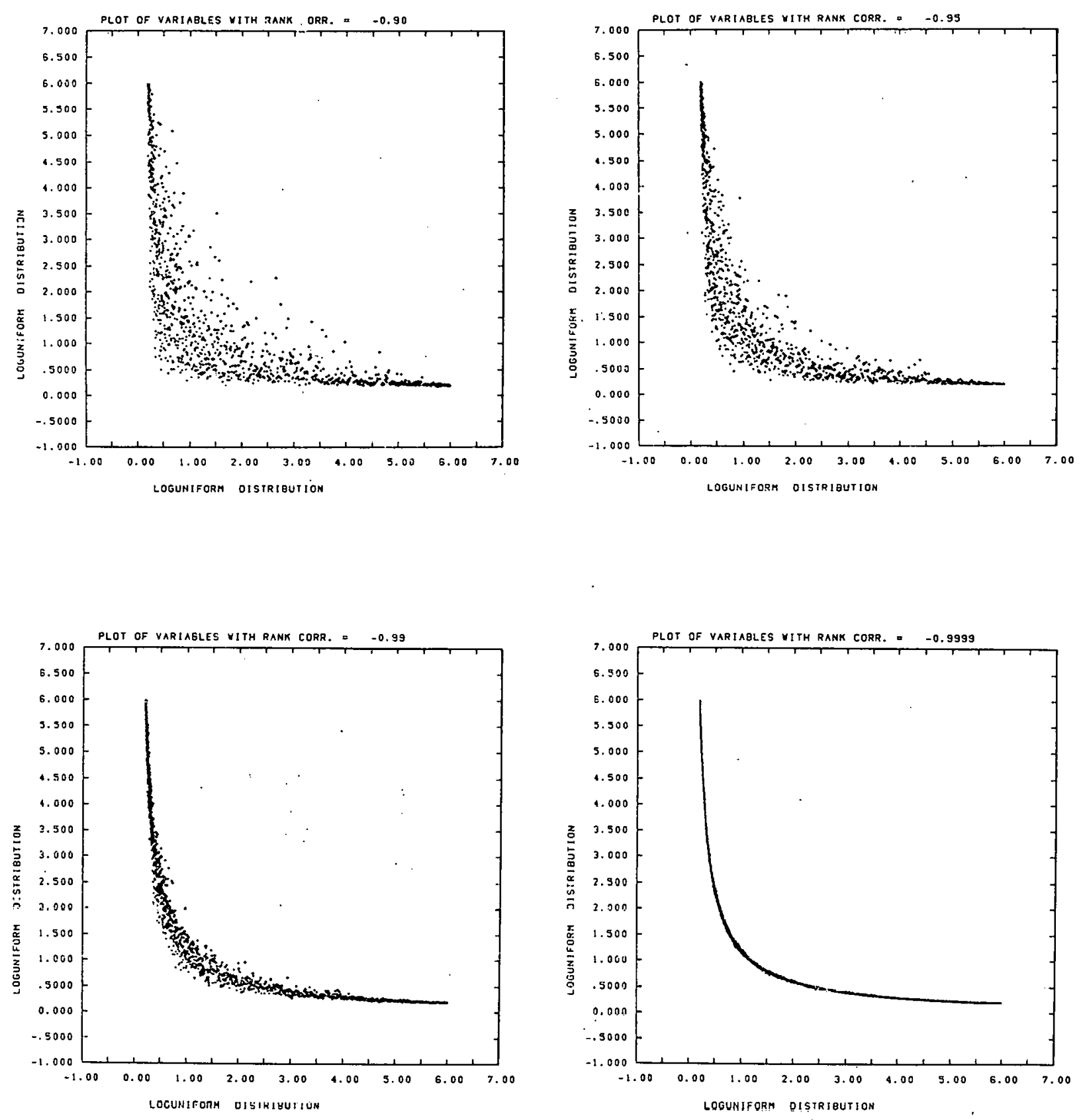

Figure $A-8$

Simulated Scattcrplots of "Jointly" Distributed Random Variables with Specified Target Rank Correlations with Sample. Size $=1000$. Case 8: Loguniform Distribution vs. Loguniform Distribution. 

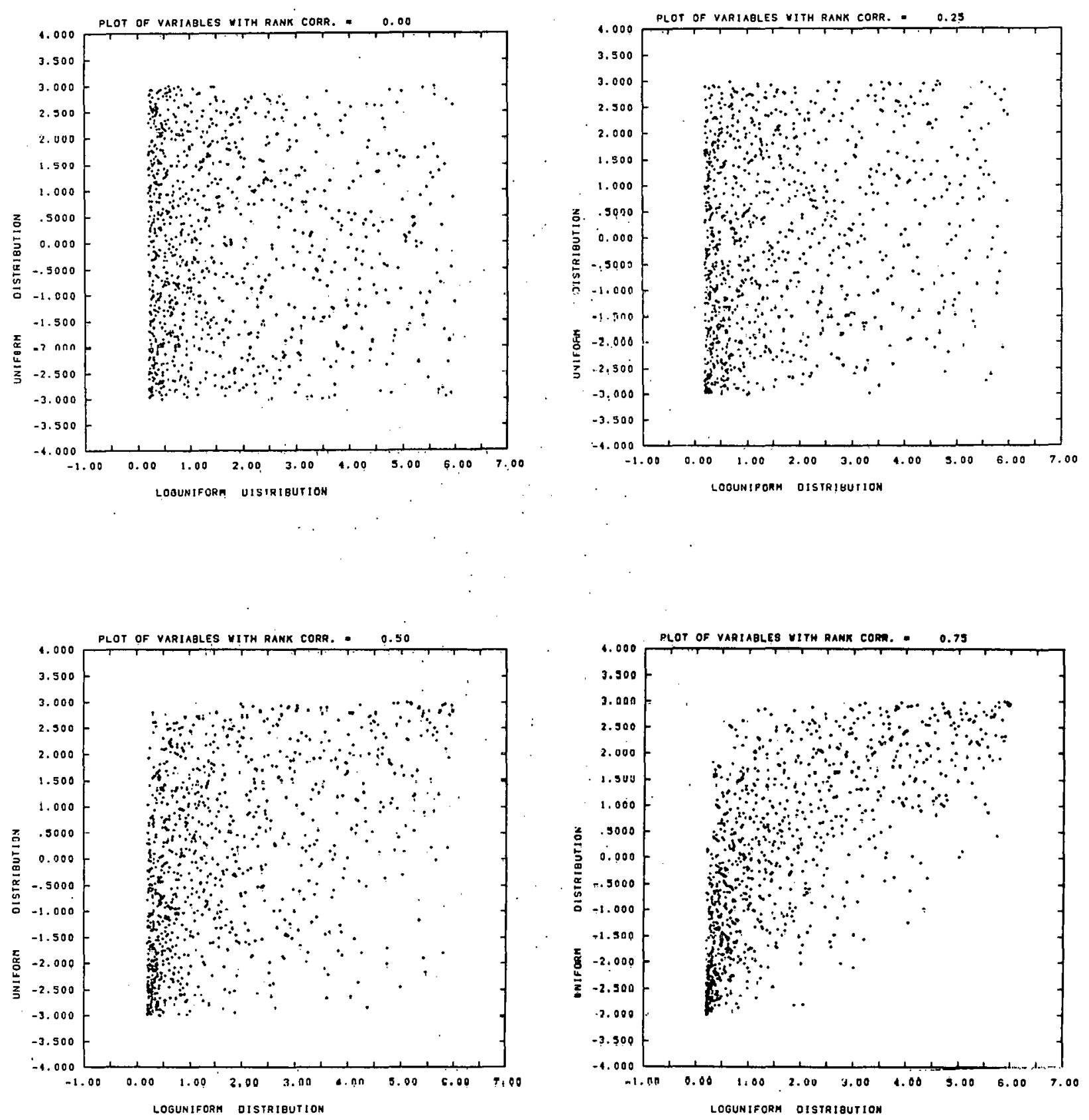

Figure $A-9$

Simulated Scatterplots of "Jointly" Distributed Random Variables with Specified Target Rank Correlations with Sample Size $=1000$.

Case 9: Loguniform Distribution vs. Uniform Distribution. 

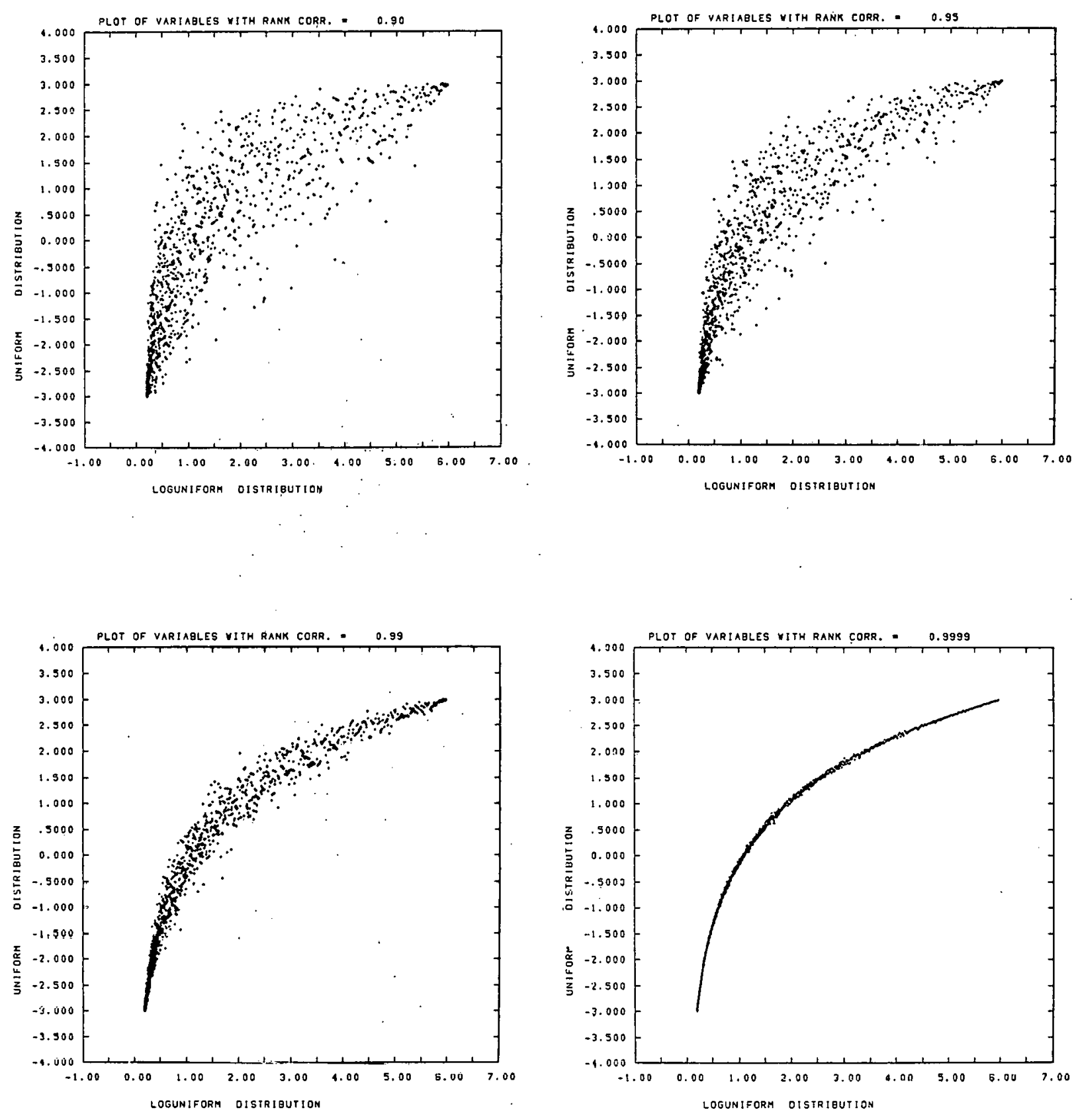

Figure $A-9$

Simulated Scatterplots of "Jointly" Distributed Random Variables with Specified Target Rank Correlations with Sample Size $=1000$. Case 9: Loguniform Distribution vs. Uniform Distribution. 

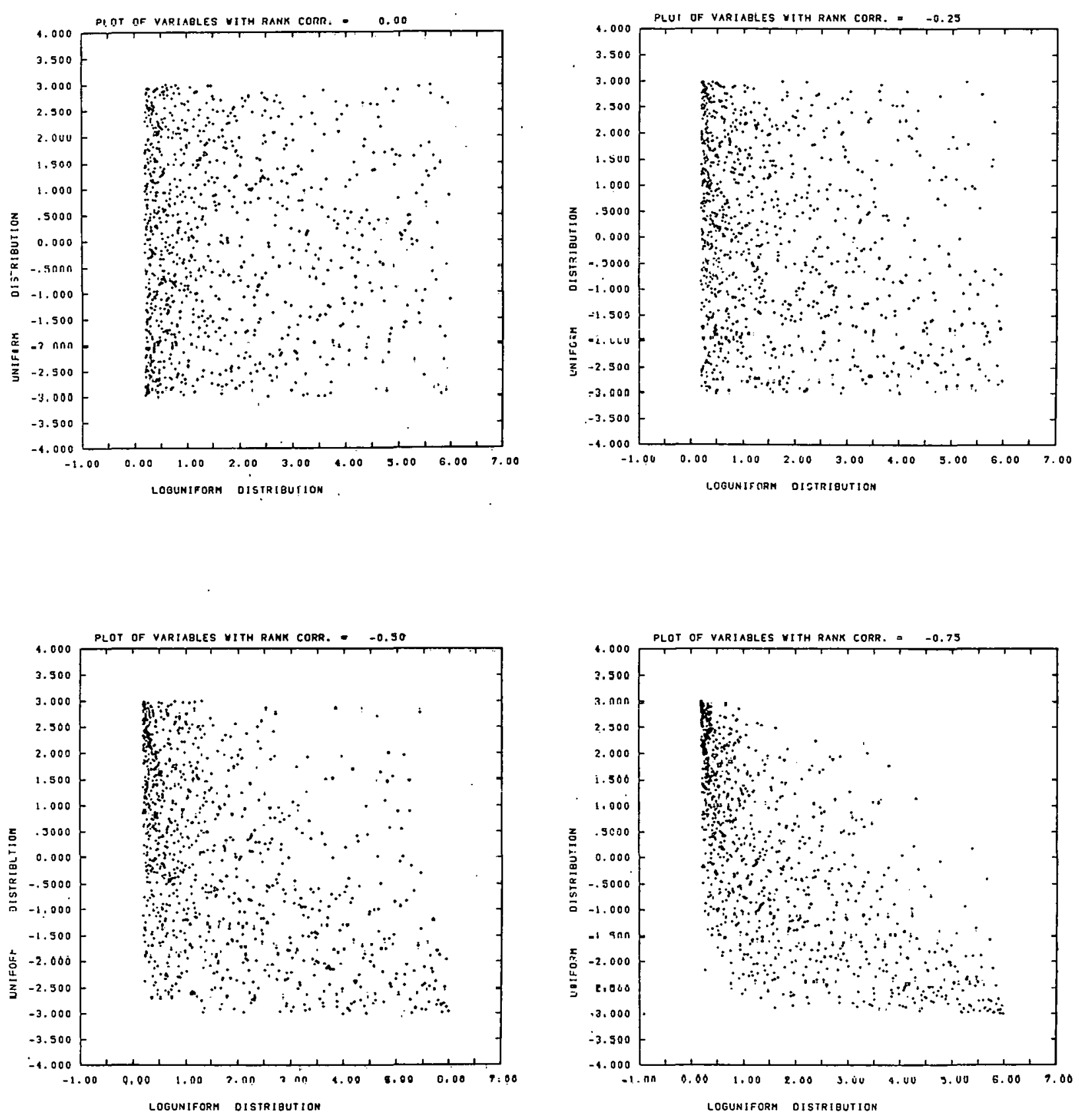

Figure $A-9$

Simulated Scatterplots of "Jointly" Distributed Random Variables with Specified Target Rank Correlations with Sample Size $=1000$.

Case 9: Loguniform Distribution vs. Uniform Distribution. 

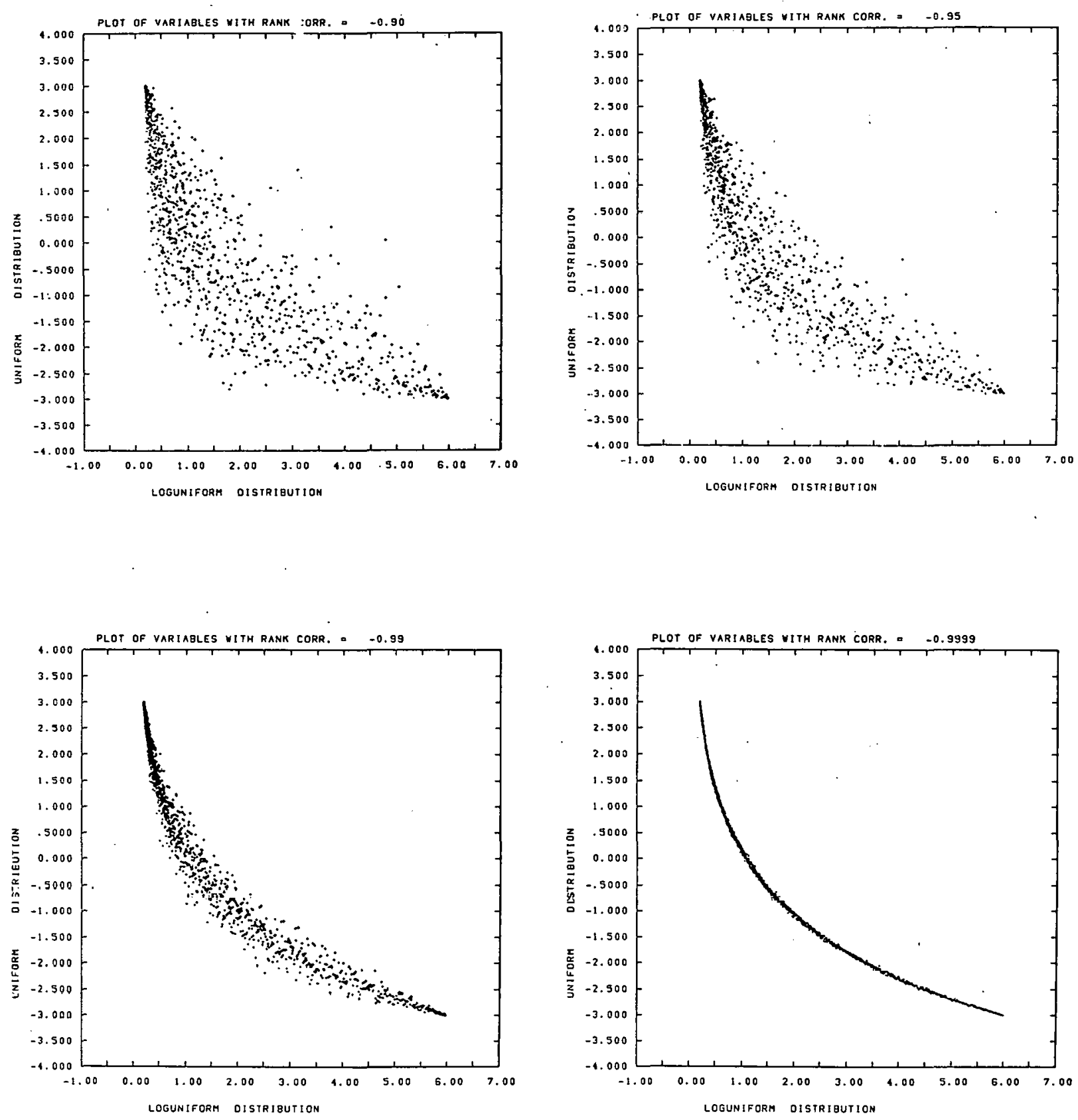

Figure $A-9$

Simulated Scatterplots of "Jointly" Distributed Random Variables with Specified Target Rank Correlations with Sample Size $=1000$. Case 9: Loguniform Distribution vs. Uniform Distribution. 

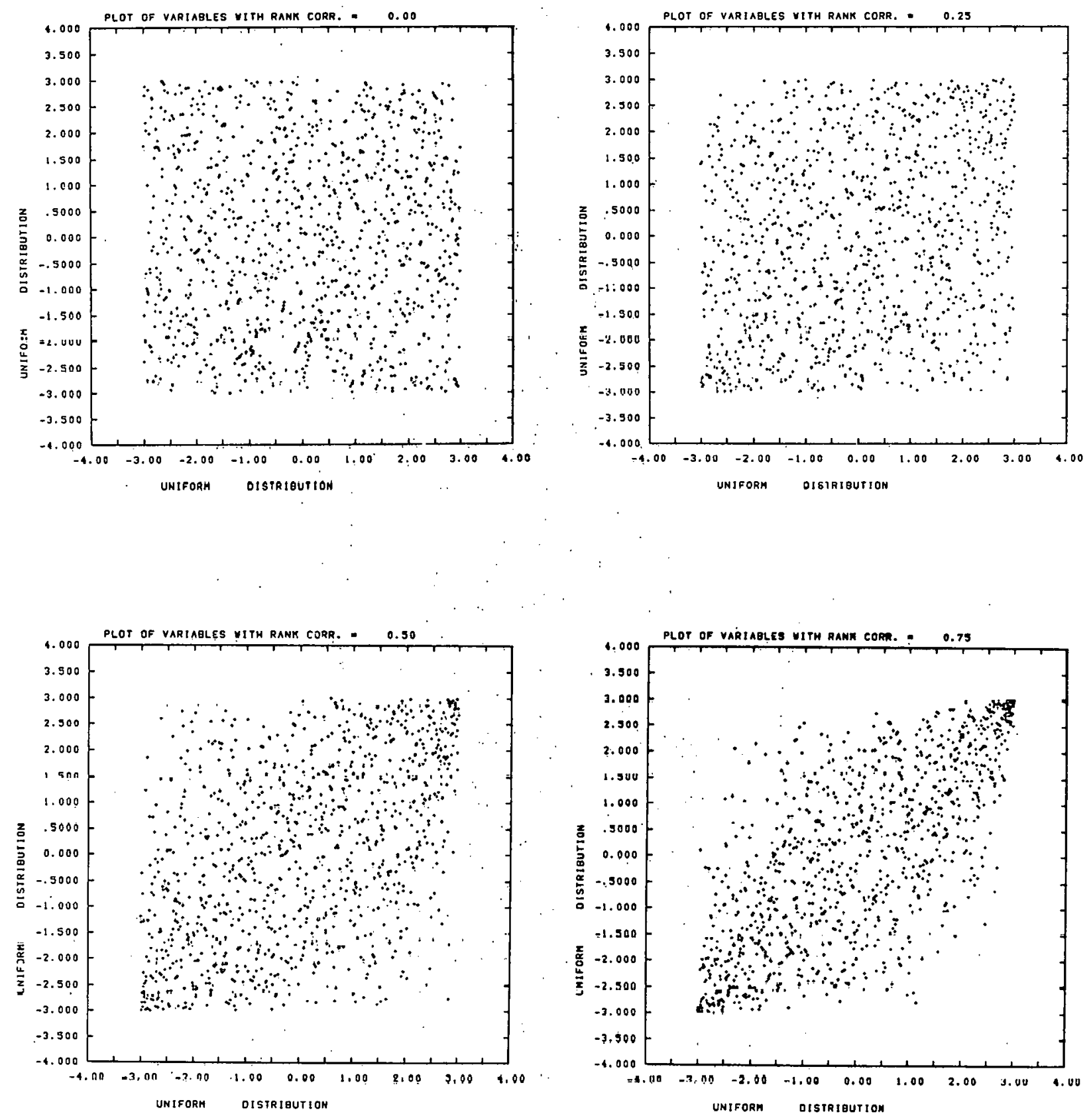

Figure $\mathrm{A}-10$

Simulated Scatterplots of "Jointly" Distributed Random Variables with Specified Target Rank Correlations with Sample Size $=1000$. Case 10: Uniform Distribution vs. Uniform Distribution. 

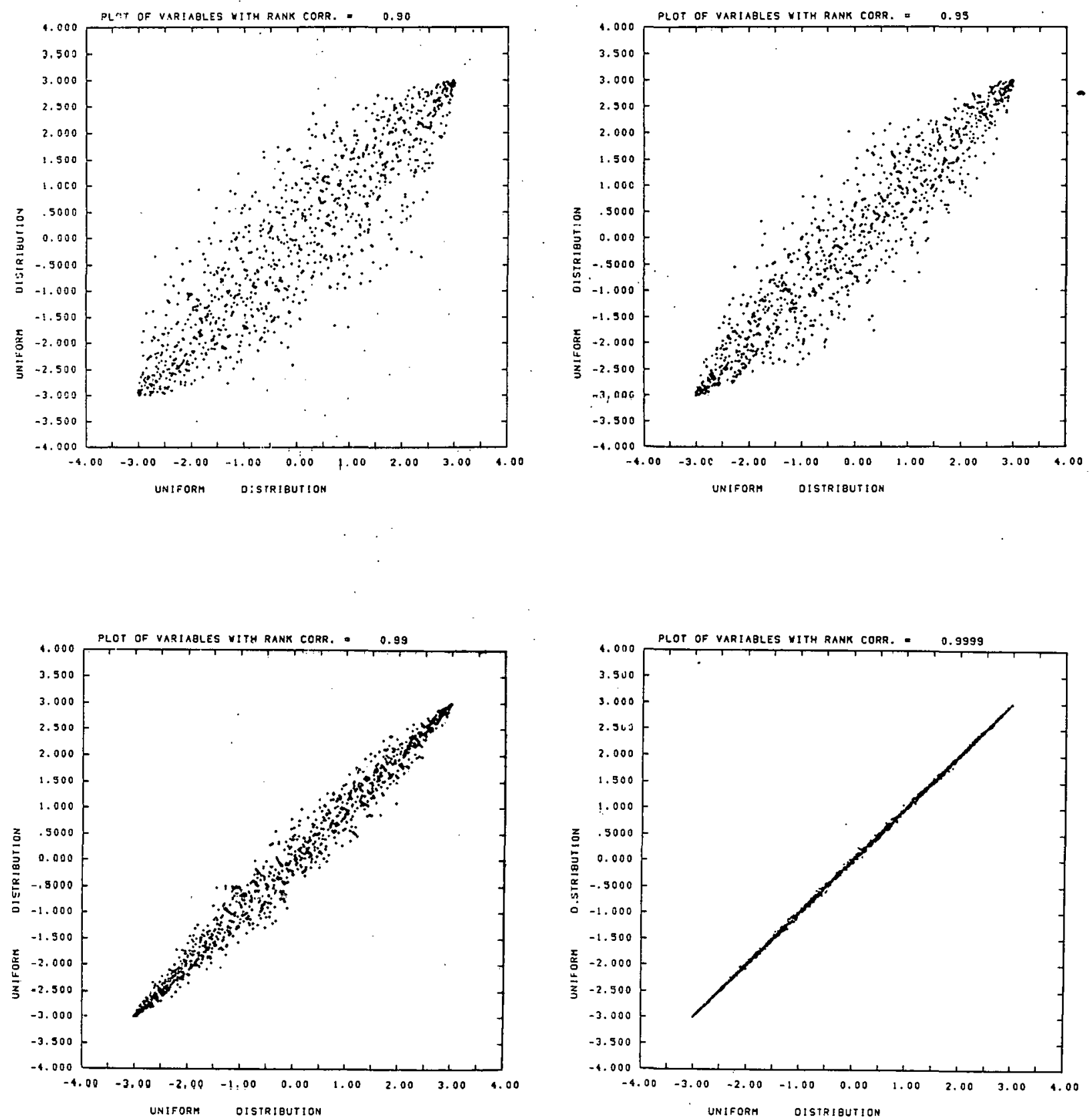

Figure $A-10$

Simulated Scatterplots of "Jointly" Distributed Random Variables with Specified Target Rank Correlations with Sample Size $=1000$. Case 10: Uniform Distribution vs. Uniform Distribution. 

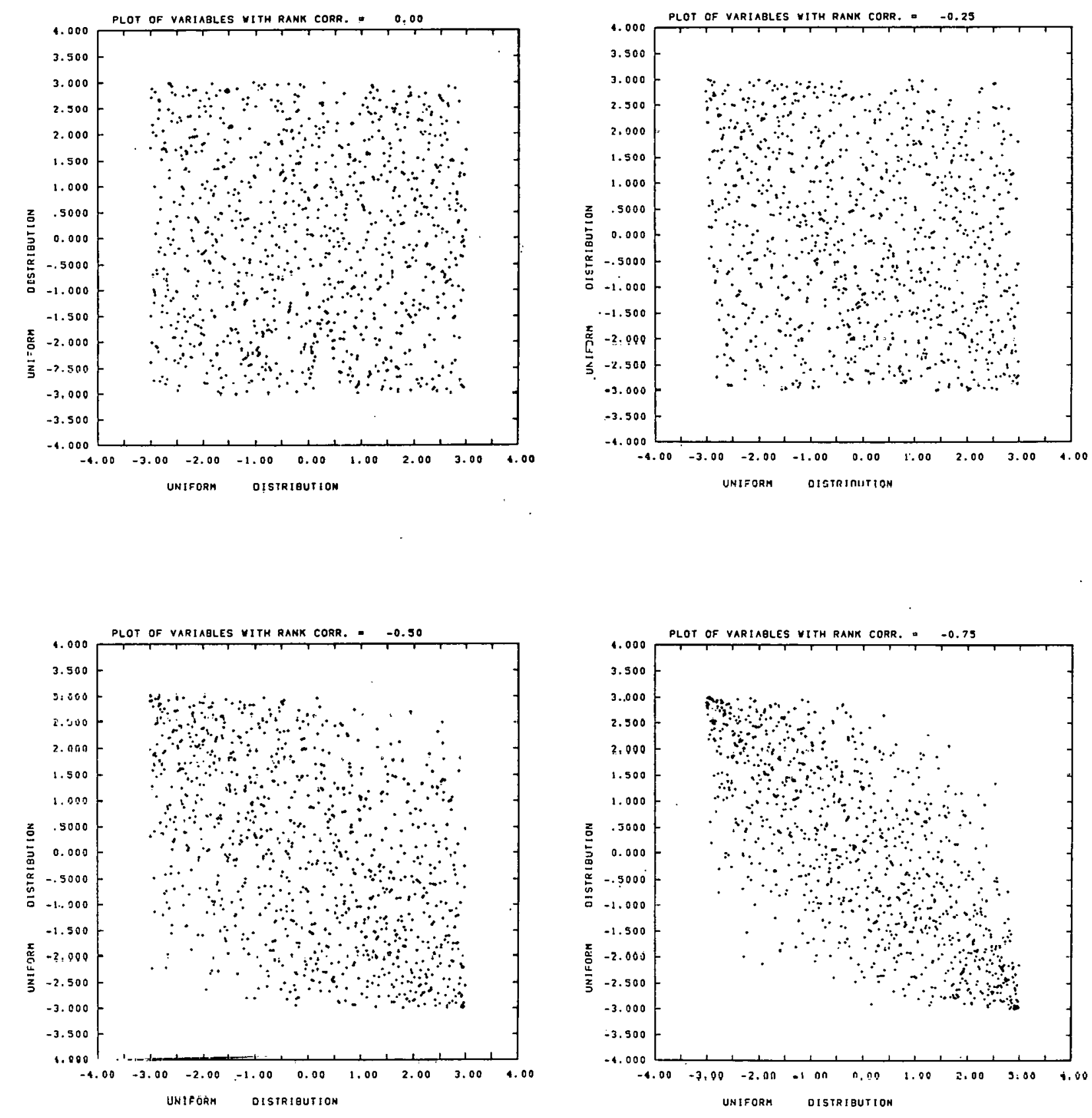

Figure $A-10$

Simulated Scatterplots of "Jointly" Distributed Random Variables with Specified Target Rank Correlations with Sample Size $=1000$. Case 10: Uniform Distribution vs. Uniform Distribution. 

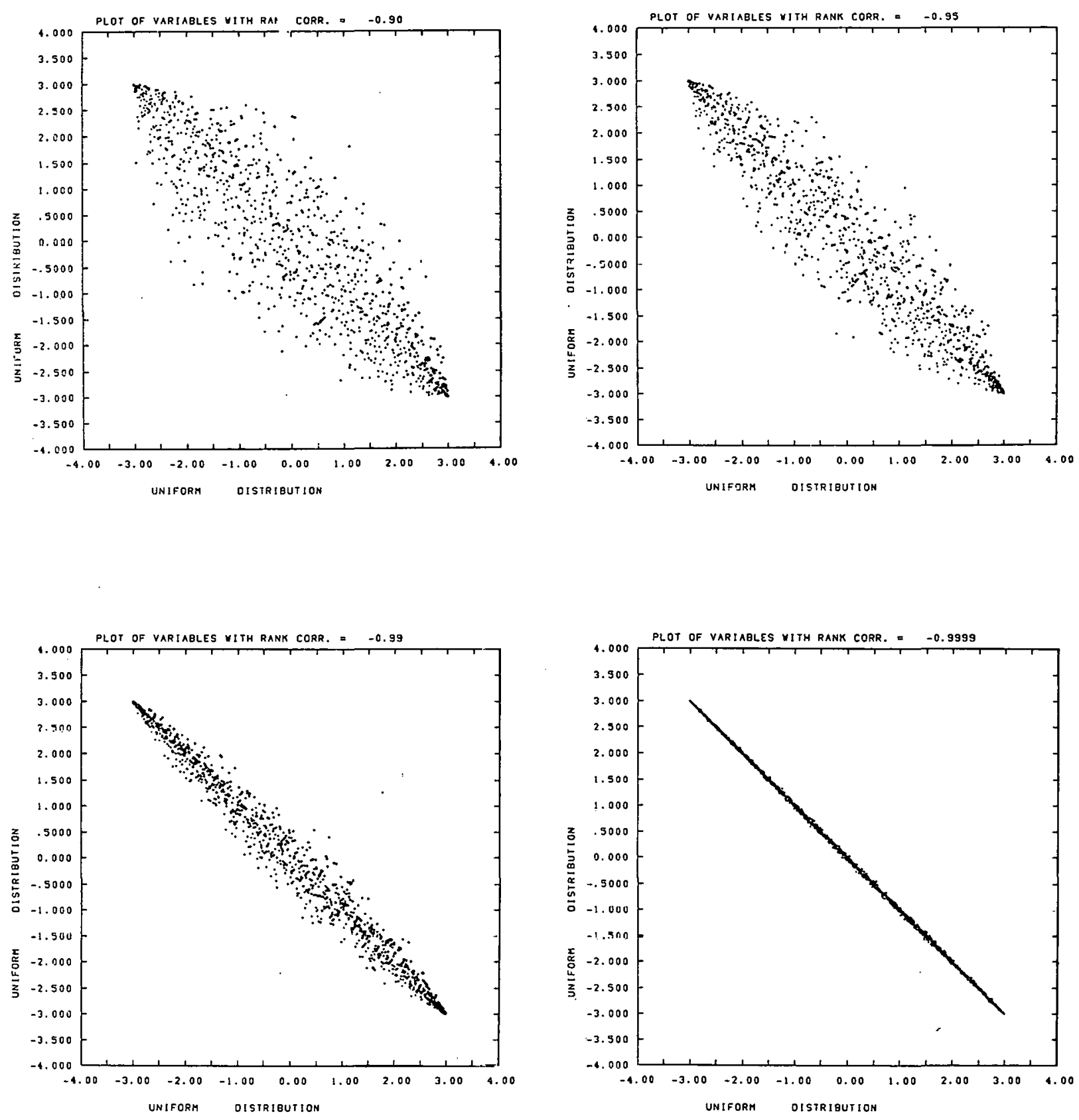

Figure $A-10$

Simulater Scatterplots of "Jointly" Distributed Random Variables with Specified Target Rank Correlations with Sample Size $=1000$. Case 10: Uniform Distribution vs. Uniform Distribution. 
THIS PAGE LEFT BLANK INTENTIONALLY. 
APPENDIX B.

Tables of the Target Rank Correlations, Sample Rank Correlations, and Sample Pearson Correlations for each of the ten pairs of "joint" distributions. 
Table B-1

Target Correlations and Realized Sample Correlations for $\mathrm{N}=1000$; Normal Distribution vs. Normal Distribution

\begin{tabular}{ccc}
$\begin{array}{c}\text { Target } \\
\text { Rank } \\
\text { Correlation }\end{array}$ & $\begin{array}{c}\text { Sample } \\
\text { Rank } \\
\text { Correlation }\end{array}$ & $\begin{array}{c}\text { Sample } \\
\text { Pearson } \\
\text { Correlation }\end{array}$ \\
\hline 0.9999 & 0.9999 & 0.9999 \\
0.99 & 0.9891 & 0.9901 \\
0.95 & 0.9444 & 0.9499 \\
0.90 & 0.8924 & 0.8999 \\
0.75 & 0.7379 & 0.7491 \\
0.50 & 0.4873 & 0.4995 \\
0.25 & 0.2381 & 0.2484 \\
0.00 & 0.0020 & -0.0070 \\
-0.25 & -0.2289 & -0.2478 \\
-0.50 & -0.4871 & -0.4998 \\
-0.75 & -0.7371 & 0.7482 \\
-0.90 & -0.8923 & -0.8999 \\
-0.95 & -0.9471 & -0.9494 \\
-0.99 & -0.9890 & 0.9899 \\
-0.9999 & -0.7999 & -0.9999
\end{tabular}


Table $B-2$

Target Correlistions and Realized Sample Correlations for $N=1000$; Nojmal Distribution vs. Lognormal Distribution

\begin{tabular}{ccc}
$\begin{array}{c}\text { Target } \\
\text { Rank } \\
\text { Correlation }\end{array}$ & $\begin{array}{c}\text { Sample } \\
\text { Rank } \\
\text { Correlation }\end{array}$ & $\begin{array}{c}\text { Sample } \\
\text { Pearson } \\
\text { Correlation }\end{array}$ \\
\hline 0.9999 & 0.9999 & 0.9300 \\
0.99 & 0.9888 & 0.9202 \\
0.95 & 0.9456 & 0.8827 \\
0.90 & 0.8958 & 0.8365 \\
0.75 & 0.7359 & 0.7017 \\
0.50 & 0.4872 & 0.4791 \\
0.25 & 0.2281 & 0.2443 \\
0.00 & 0.0002 & -0.0277 \\
-0.25 & -0.2346 & -0.2372 \\
-0.50 & -0.4908 & -0.4717 \\
-0.75 & -0.7289 & -0.7006 \\
-0.90 & -0.8880 & -0.8389 \\
-0.95 & -0.9454 & -0.8820 \\
-0.99 & -0.9889 & -0.9206 \\
-0.9999 & -0.9999 & -0.9301
\end{tabular}


Table $B-3$

Target Correlations and Realized Sample Currelations for $\mathrm{N}=1000$; Normal Distribution vs: Loguniform Distribution

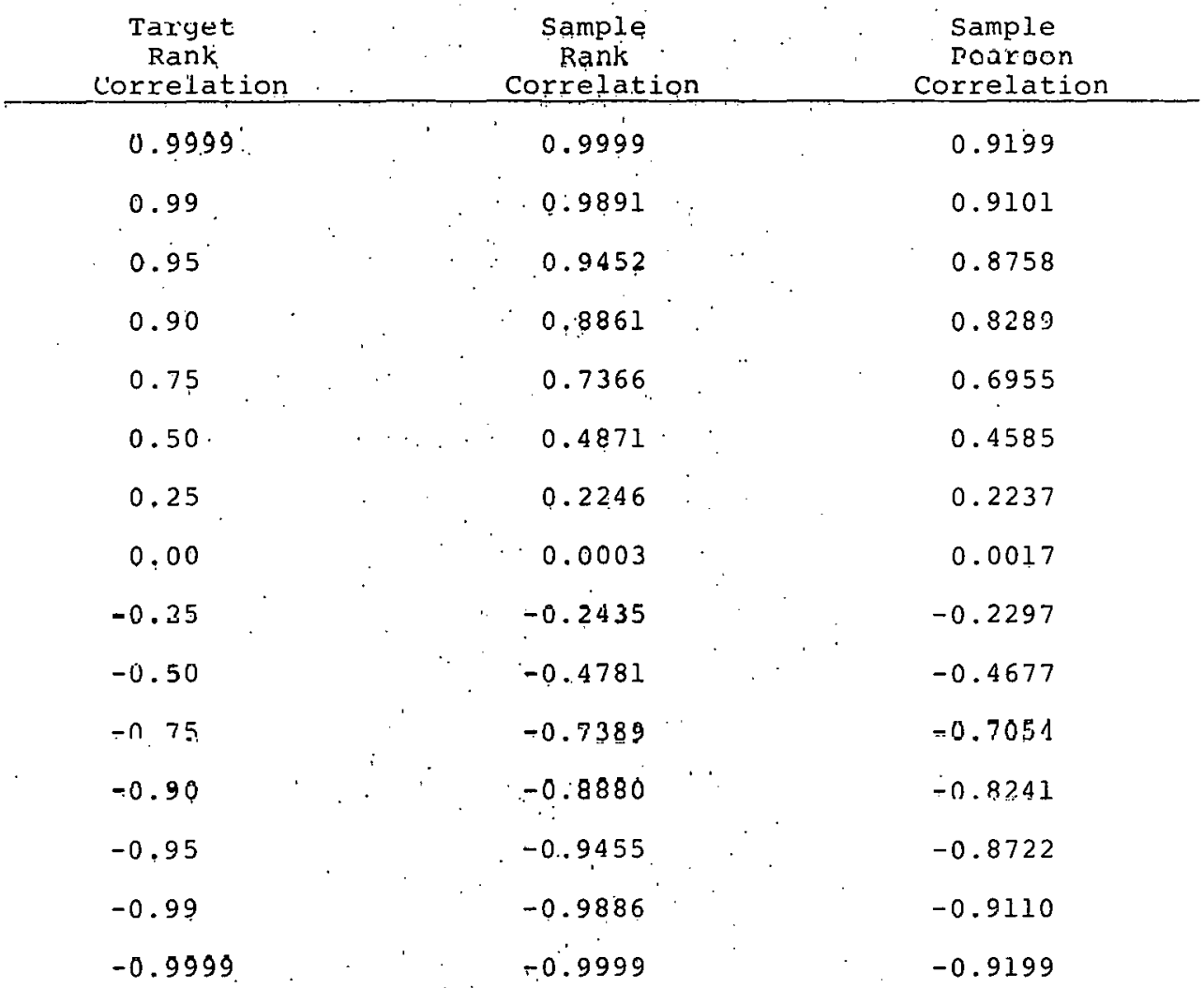


Table B-4

Target Correlations and Realized Sample Correlations for $\mathrm{N}=1000$ Normal Distribution vs, Uniform Distribution

\begin{tabular}{ccc}
$\begin{array}{c}\text { Target } \\
\text { Rank } \\
\text { Correlation }\end{array}$ & $\begin{array}{c}\text { Sample } \\
\text { Rank } \\
\text { Correlation }\end{array}$ & $\begin{array}{c}\text { Sample } \\
\text { Pearson } \\
\text { Correlation }\end{array}$ \\
\hline 0.9999 & 0.9999 & 0.9778 \\
0.99 & 0.9891 & 0.9680 \\
0.95 & 0.9431 & 0.9278 \\
0.90 & 0.8895 & 0.8799 \\
0.75 & 0.7329 & 0.7310 \\
0.50 & 0.4842 & 0.4876 \\
0.25 & 0.2332 & 0.2452 \\
0.00 & 0.0001 & 0.0132 \\
-0.25 & -0.2379 & -0.2330 \\
-0.50 & -0.4818 & -0.4864 \\
-0.75 & -0.7352 & -0.7342 \\
-0.90 & -0.8915 & -0.8802 \\
-0.95 & -0.9481 & -0.9309 \\
-0.99 & -0.9891 & -0.9684 \\
-0.9999 & -0.9999 & -0.9779 \\
& &
\end{tabular}


Table B-5

Target Correlations and Realized Sample Correlations for $\mathrm{N}=1000$; Lognormal Distribution vs. Loynurnal Distribution

\begin{tabular}{ccc}
$\begin{array}{c}\text { Target } \\
\text { Rank } \\
\text { Culieldidun }\end{array}$ & $\begin{array}{c}\text { Sample } \\
\text { kank } \\
\text { Correlation }\end{array}$ & $\begin{array}{c}\text { Sample } \\
\text { Pearson } \\
\text { Correlation }\end{array}$ \\
\hline 0.9999 & 0.9999 & 0.9997 \\
0.99 & 0.9892 & 0.9879 \\
0.95 & 0.9472 & 0.9355 \\
0.90 & 0.8924 & 0.8919 \\
0.75 & 0.7315 & 0.7045 \\
0.50 & 0.4733 & 0.4997 \\
0.25 & 0.2452 & 0.2228 \\
0.00 & 0.0013 & -0.0293 \\
-0.25 & -0.2461 & -02072 \\
-0.50 & -0.4837 & -0.3952 \\
0.75 & -0.7263 & -0.5818 \\
-0.90 & -0.8952 & -0.6871 \\
-0.95 & -0.9439 & -0.7169 \\
-0.99 & -0.9889 & -0.7441 \\
-0.9999 & -0.9999 & -0.7479 \\
& &
\end{tabular}


Target Correlations and Realized Sample Correlations for $N=1000$; Lognormal Distribution vs. Loguniform Distribution

\section{-}

\begin{tabular}{ccc}
$\begin{array}{c}\text { Target } \\
\text { Rank } \\
\text { Correlation }\end{array}$ & $\begin{array}{c}\text { Sample } \\
\text { Rank } \\
\text { Correlation }\end{array}$ & $\begin{array}{c}\text { Sample } \\
\text { Pearson } \\
\text { Correlation }\end{array}$ \\
\hline 0.9999 & 0.9999 & 0.9592 \\
0.99 & 0.9888 & 0.9478 \\
0.95 & 0.9474 & 0.9080 \\
0.90 & 0.8912 & 0.8579 \\
1 & 0.7363 & 0.6984 \\
0.75 & 0.4898 & 0.4625 \\
0.25 & 0.2423 & 0.2290 \\
0.00 & 0.0019 & 0.0147 \\
-0.25 & -0.2556 & -0.2005 \\
-0.50 & -0.4895 & -0.3950 \\
-0.75 & -0.7394 & -0.5657 \\
-0.90 & -0.8928 & -0.6644 \\
-0.95 & -0.9457 & -0.6985 \\
-0.99 & -0.9886 & -0.7231 \\
-0.9999 & -0.9999 & -0.7257 \\
& &
\end{tabular}


Tablè $B-7$

Target Correlations and Realized Sample Correlations for $\mathrm{N}={ }^{\prime} 1000$; Lognormal Distribution vs. Uniform Distribution

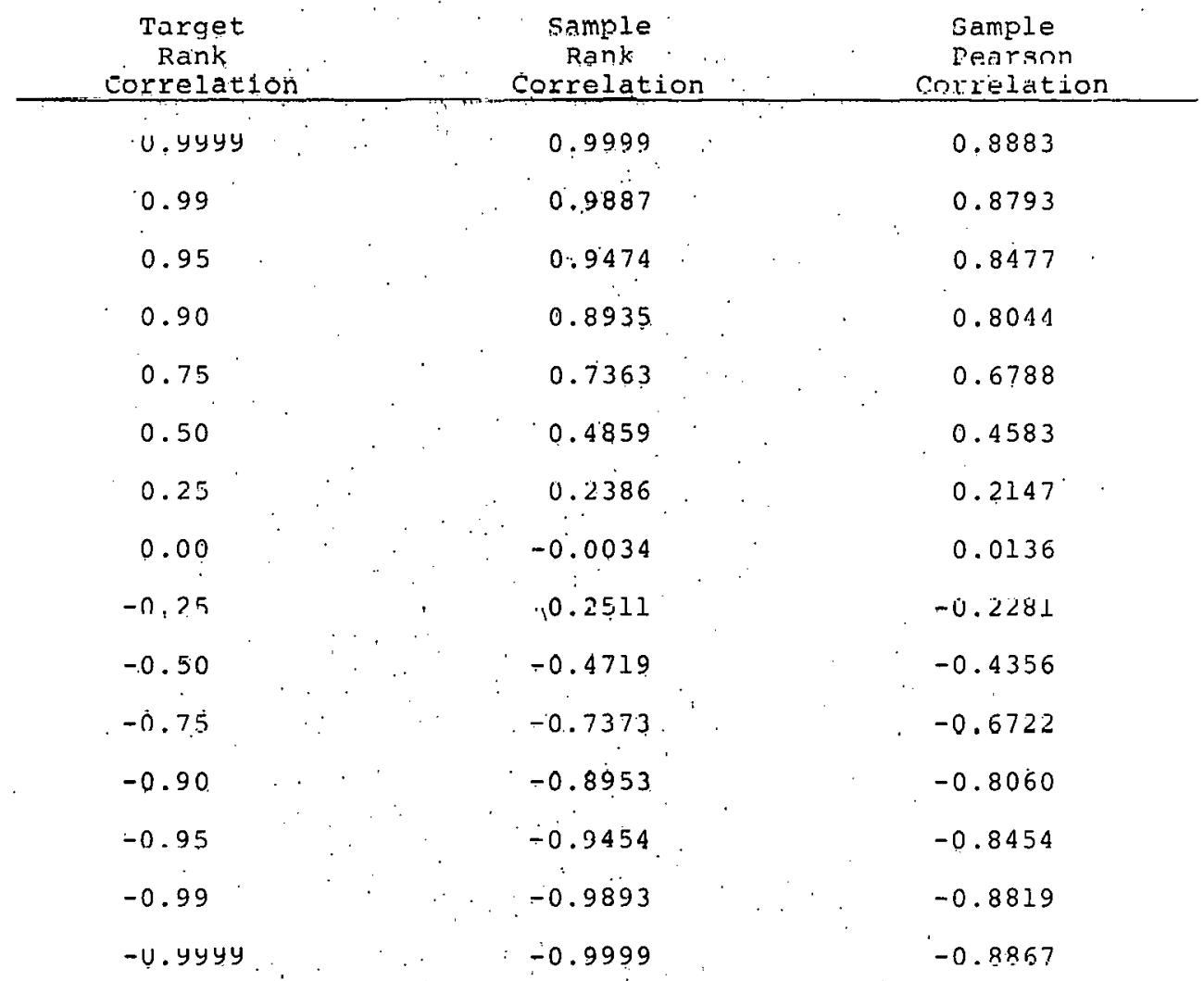


Table $B-8$

Target Correlations and Realized Sample Correlations for $N=1000$; Loguniform Distribution vs. Loguniform Distribution

\begin{tabular}{ccc}
$\begin{array}{c}\text { Target } \\
\text { Rank } \\
\text { Correlation }\end{array}$ & $\begin{array}{c}\text { Sample } \\
\text { Rank } \\
\text { Correlation }\end{array}$ & $\begin{array}{c}\text { Sample } \\
\text { Pearson } \\
\text { Correlation }\end{array}$ \\
\hline 0.9999 & 0.9999 & 0.9998 \\
0.99 & 0.9885 & 0.9881 \\
0.95 & 0.9435 & 0.9405 \\
0.90 & 0.8894 & 0.8905 \\
0.75 & 0.7280 & 0.7169 \\
0.50 & 0.4793 & 0.4508 \\
0.25 & 0.2362 & 0.2068 \\
0.00 & 0.0023 & -0.0303 \\
-0.25 & -0.2465 & -0.2105 \\
-0.50 & -0.4736 & -0.3871 \\
-0.75 & -0.7261 & -0.5674 \\
-0.90 & -0.8875 & -0.6595 \\
-0.95 & -0.9460 & -0.6909 \\
-0.99 & -0.9887 & -0.7126 \\
-0.9999 & -0.9999 & -0.7180 \\
& &
\end{tabular}


Table B-9

Target Correlations and Realized Sample Correlations for $\mathrm{N}=1000$; Loguniform Distribution vs. Uniform Distribution

\begin{tabular}{ccc}
$\begin{array}{c}\text { Tarqct } \\
\text { Rank } \\
\text { Correlation }\end{array}$ & $\begin{array}{c}\text { SAllulp } \\
\text { Rank } \\
\text { Correlation }\end{array}$ & $\begin{array}{c}\text { Samplo } \\
\text { Pearson } \\
\text { Correlation }\end{array}$ \\
\hline 0. yygy & 0.9999 & 0.9210 \\
0.99 & 0.9890 & 0.9110 \\
0.95 & 0.9454 & 0.8728 \\
0.90 & 0.8955 & 0.8251 \\
0.75 & 0.7371 & 0.6860 \\
0.50 & 0.4817 & 0.4422 \\
0.25 & 0.2119 & 0.2327 \\
0.00 & -0.0002 & -0.0123 \\
-0.25 & -0.2443 & $-0.240 \%$ \\
-0.50 & -0.4904 & -0.4733 \\
-0.75 & -0.7252 & -0.6821 \\
-0.90 & -0.8918 & -0.8253 \\
-0.95 & -0.9463 & -0.8731 \\
-0.99 & -0.9893 & -0.9119 \\
-0.9999 & -0.9999 & -0.9710 \\
& &
\end{tabular}


Table 10

Target Correlations and Realized Sample Correlations for $\mathrm{N}=1000$; Uniform Distribution vs. Uniform Distribution

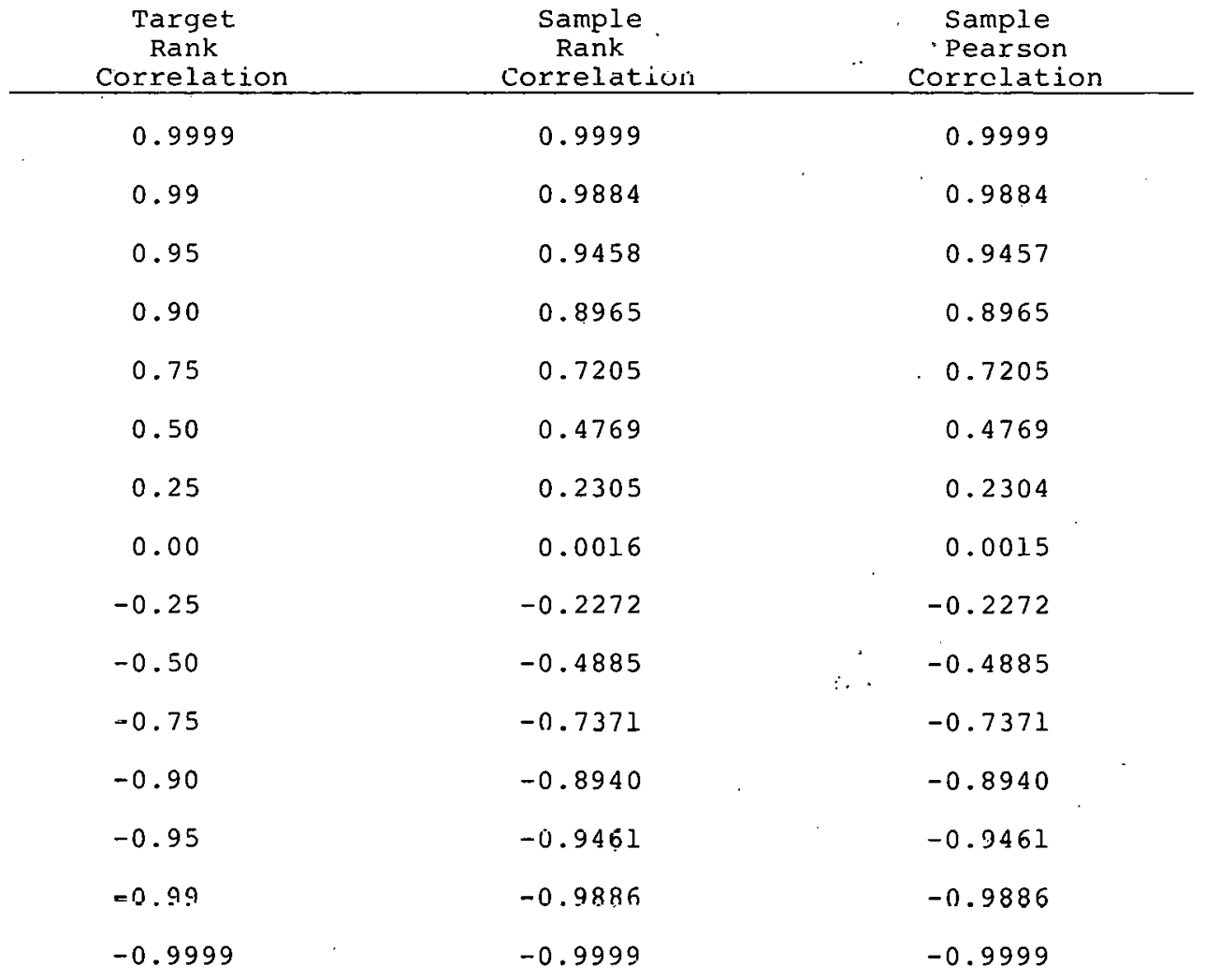


Distribution:

Intera Environmental Consultants, Inc. (5)

1511 Katy Freeway, Sulte 630

Houston, TX 7079

Attn: R. B. Lantz

J. E. Campbe11 (4)

Los Alamos Scientiftc Lab. (5).

Group S1, MS606

Los Alamos, N.M. 87545

Attn: R. A. Waller

R. J. Beckman

M. E. Johnson

M. D. McKay

G. L. Tletjen

W. J. Conover (2)

College of Business Admin.

P. D. Box 4320

Lubbock, TX 79409

J. M. Davenport (10)

Dept. of Mathematics.

P. 0. Box 4319

Lubbock, Tx 79409 .

Dept. of Statistics (2)

Kansas State Unfversity

Manhattan, $\bar{K} \bar{S} 66506$

Attn: G. A. Milliken

D. E. Johnion

D. A. Gardiner (2)

Computer Sciences Div., UCND.

P. O. Box Y

Oak Ridge, TN 37830
1223 R. R. Pratirte
1223 K. V. Diegert
1223 I. J. Ha11
1223 R. L. Iman (25)
1223 D. D. Sheldon
1223 M. .T. 3hortencarler
1425 E. E. Ard
1425 F. W. Muller
1425 F. Spencer
4413 R. M. Cranwell
4413 J. C. Helton
4530 R. W. Lynch
4537 B. S. Langkopf

W. R. Schucany

Dept. of Statistics

Southern Methodist University

Dallas, TX 75275
4537

4538

4538

4538

4538

4731

3141

3151
L. D. Tÿler

R. C. Lincoln

S. Sinnock

H. P. Stephens (5)

R. Link

H. Y. Stephens (5)

T. L. Werner (5)

W. L. Garner (3)

for DOE/TIC (Unlimited Release) 
Iman, R. L. and Conover, W. J. (1980a). Small Sample Sensitivity Analysis Techniques for Computer Models, with an Application to Risk Assessment. Commun. in Stat1st., $A 9(17)$, to appear.

Iman, R. L. and Conover, W. J. (1980b). Risk Methodology for Geologic Disposal of Radioactive Waste: A Distribution-Free Approach to Inducing Rank Correlation Among Input Varlables for Simulation Studies. Tech. Report SAND80-0157, Sandia Laboratorles, Albuquerque, NM.

Iman, R. L. and Conover, W. J. (1981). A Distribution-Free Approach to Inducing Rank Correlation Among Input Varlables for Simulation Studies. Submitted for publication to Technometrics.

Iman, R. L., Davenport, J. M., and 7elgler, D. K. (1980). Lat1n Hypercube Sampling (A Program User's Gulde). Tech. Report SAND79-1473, Sandia Laboratorfes, Albuquerque, NM.

Love, S. K. (1956). Quality of Surface Waters of the United States 1952, Parts 7-8 Lower Mississipp1 RIver Basin and Western Gulf of Mexico Basks U. S. Geological Survey Water-Supply Paper 1252, p. 380-381.

McKay, M. D., Conover, W. J., and Beckman, R. J. (1979). A compar1son of Three Methods for Selecting Values of Input Variables in the Analysis of Output from a Computer Code. Technometr1cs, 21, 239-245.

Musket, M. (1937). The Flow of Homogeneous Fluids Through Porous Media; McGraw Hill Pub. Co., New York, New York.

Scheuer, E. M . and Stoller, D. S. (1962). On the Generation of Normal Random Vectors. Technometrics, 4 278-281. 


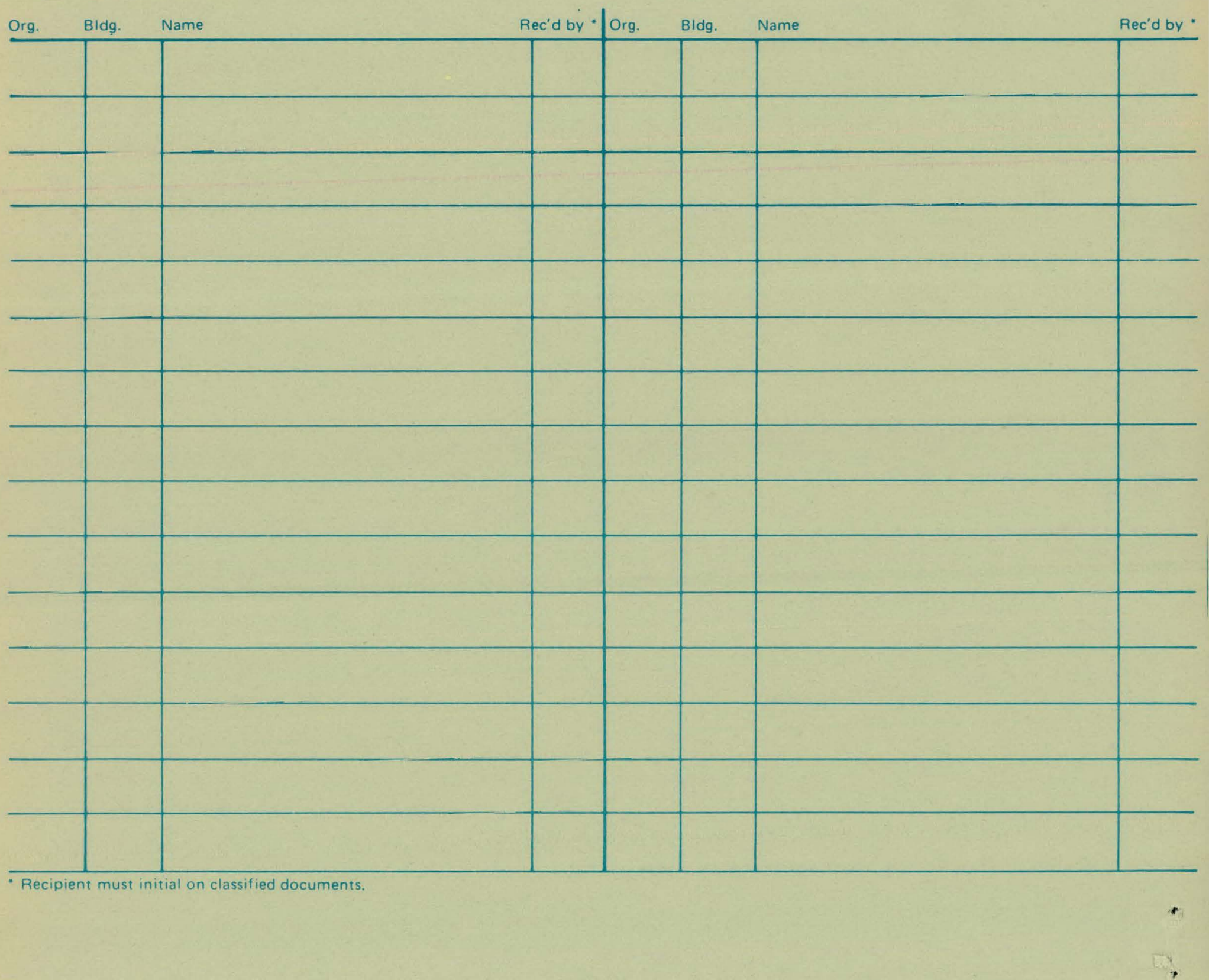

